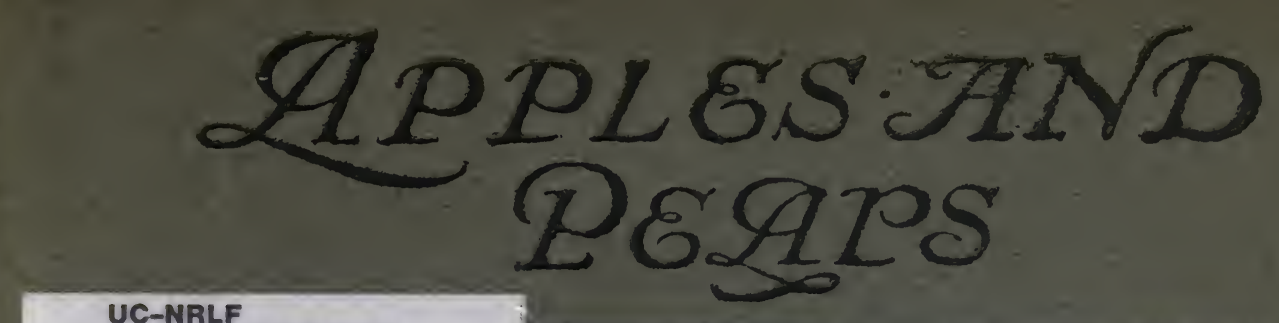

|||||

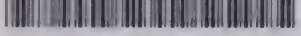
\$B ? ? 708

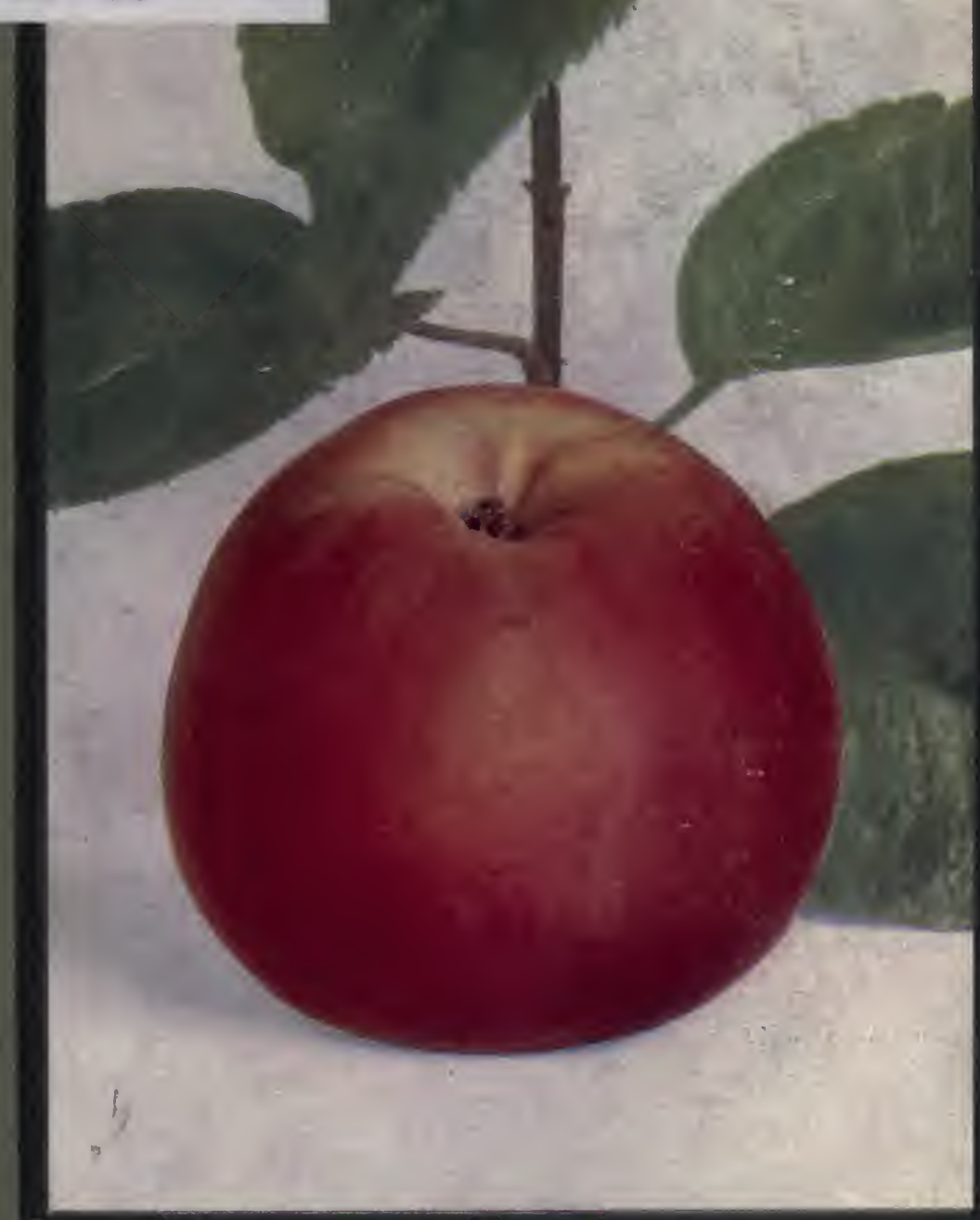

RRESENT DAY GARDENING 





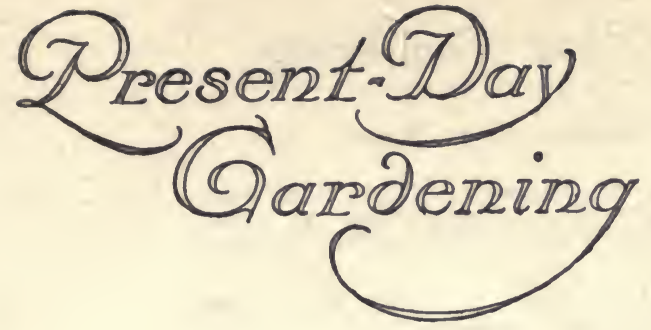

EDITED BY . . . .

R. HOOPER PEARSON MANAGING EDITOR OF THE GARDENERS CHRONICLE. . . .

A LIST OF VOLUMES IN THE SERIES IS GIVEN ON THE NEXT PAGE. 


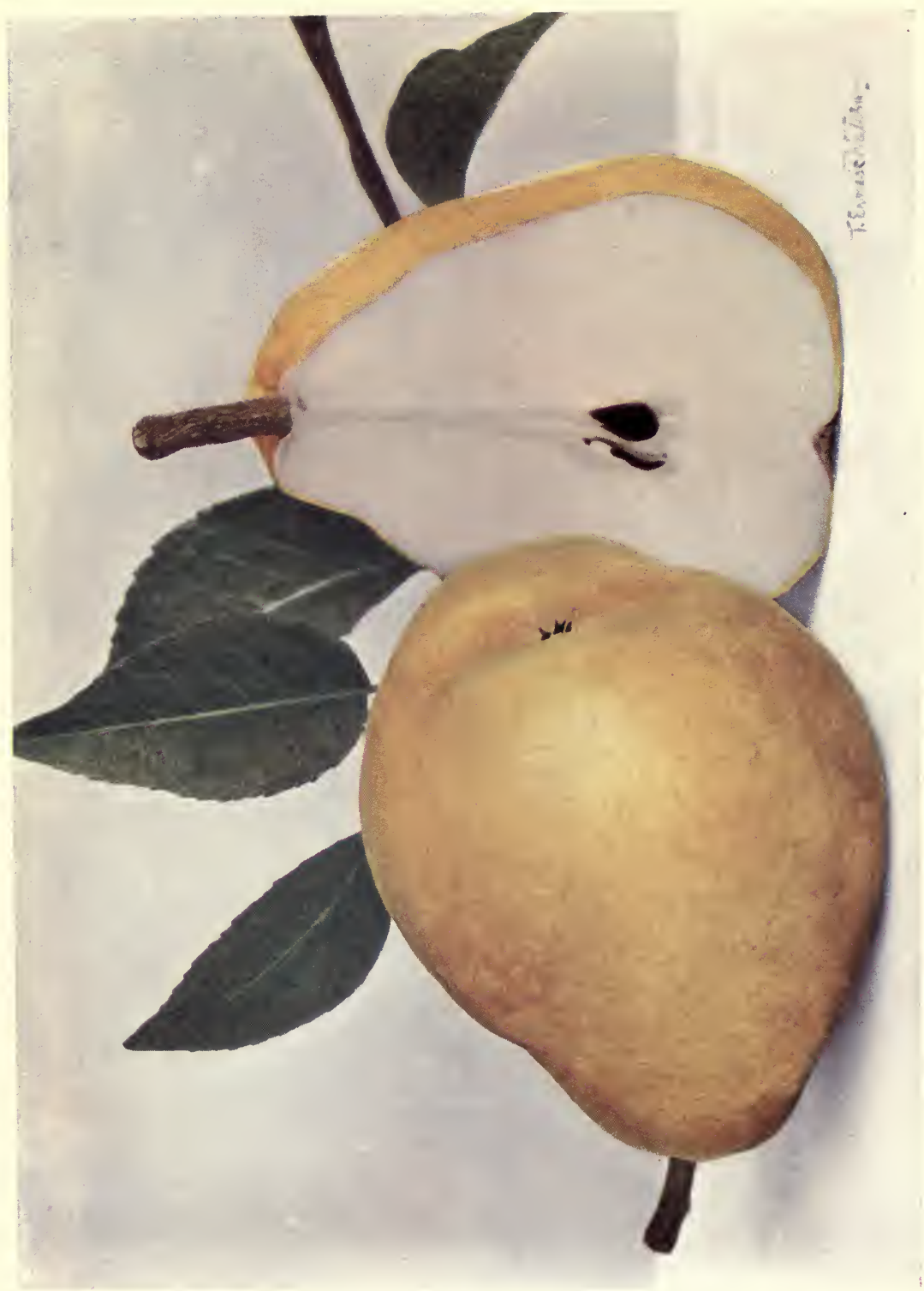




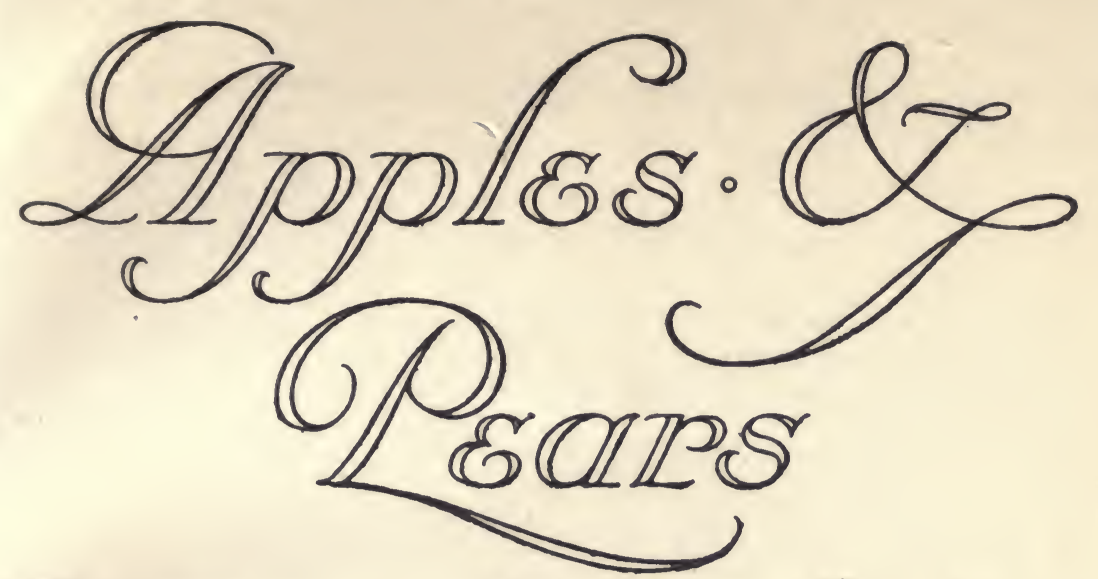

By Gropge Bunyard, v.м.н with orght Poloured
Platos

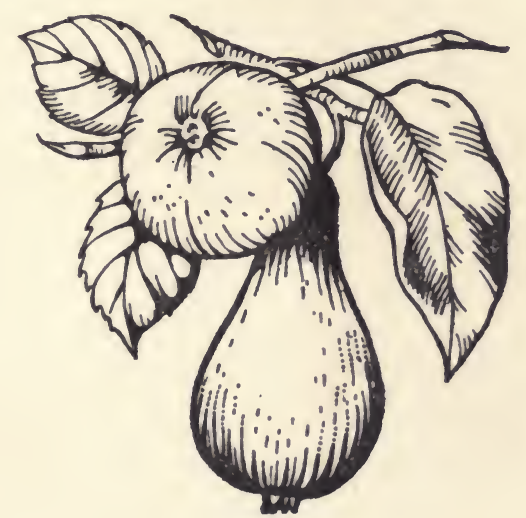

Lonan: Je.\&E.C.Jak 16 Heneistta St., w.e., \& Edinburgh 
gipt of Dancrost. 


\section{PREFACE}

NotwithstANDiNG all that has been written on the cult1vation of Apples and Pears, it still remains a reproach to us that of the many who possess the necessary means only a few have an intelligent knowledge of the details of cultivation. With the spread of education in the towns, the public has shown a greater appreciation for fruit as a regular part of the general diet, and the increased demand which has resulted has been met mainly by imports from abroad. The change in the national diet has not proved such a stimulus to home cultivators as might reasonably have been expected, and people who possess every convenience themselves for cultivating sufficient fruit to satisfy the requirements of the home may be seen cheerfully purchasing Apples, Pears, and other fruits in the nearest market. Consumers are grateful to colonial and other cultivators abroad for the supplies of fruit they send to British markets, because much of this produce arrives early in spring and in summer when British hard fruits are not in season, but we should not be unmindful of the fact that it is our duty to produce in English orchards and gardens the greatest amount of wholesome fruits it is possible for us to obtain. That this view is not entertained universally is sufficiently attested in the waste ground that may be seen around rural dwellings, including bare walls and farm buildings which are capable of providing excellent situations for fruit-trees.

But beyond the waste of opportunity that arises from lack of planting, there is the common neglect of the trees themselves, at once a misfortune and shame to some 
of the counties. In many cases it would appear that the interest does not last beyond the planting, and that afterwards the trees are left entirely to themselves, without the least care even to preserve them from the attacks of insect pests and fungous diseases. The occasional crops the trees are capable of producing in these conditions are gathered often without much care, and in seasons when fruits are scarce the blame is placed upon the trees. In many instances fruit-trees are permitted to encumber the ground long after they have ceased to be profitable, and in others the varieties are unsuited for the locality or for the positions they occupy.

It is hoped that the present volume will induce many to take up Apple and Pear culture with the determination to succeed. If they do this they are not likely to regret the step taken, for the pleasures of the fruit-grower are just as real as the delights of the flower gardener, whilst the habits of the trees are no less interesting than those of the showiest flowers-indeed the interest is carried a step further, for the flowering is merely the preparatory stage for a bountiful harvest.

Mr. Bunyard has given practical advice on the details of cultivation, both in the private fruit-garden and in the homestead where fruit is cultivated for market. From his great experience, also, he has made selections of varieties both of Pears and Apples for various purposes, and to save the reader any confusion the lists have been kept moderately short. It should be added that the fruits depicted in Mr. Waltham's colour-photographs were all cultivated by the author.

THE EDITOR. 


\section{CONTENTS}

\section{PART I}

CHAP.

I. Historical Notes . • • . • . . I

II. Purchase of Trees and Choice of Positions . Io III. Preparation of the Soll and Planting • • 15

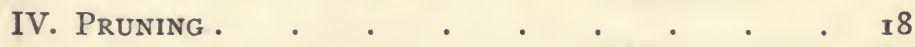

V. Root-Pruning . . . . . . . 23

VI. Select Lists of Apples . . . . . . . 27

VII. Apples and Pears for Orchard Houses • • 35

VIII. Feeding and thinning OUtdoor Trees • $\quad 47$

IX. Choice Pears for Outdoor Culture • • • 49

X. Gathering and Storing the Fruit . . . 5 I

XI. Pests of the Apple . . . . . . 54

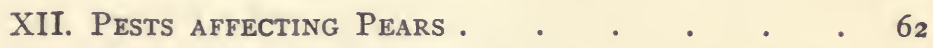

XiII. Calendar of Operations in Home Fruit

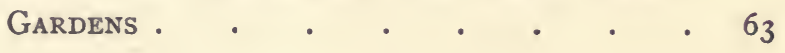

\section{PART II}

XIV. Cultivation of Apples and Pears for Profit . 66

XV. Preparation of the Land and Planting • 72

XVI. Apples For The Markets • • • • • $\quad$ - 75 
CHAP.

XVII. Choice Pears for Bushes

XVIII. Pears as Standards

XIX. Number of Trees Per ACre . . . . 80

XX. Probable Market Prices . . . . 82

XXI. Packing Fruit For Sale $\cdot$. $\cdot$. $\quad . \quad 83$

XXII. Ways and Means . . . . . . 86

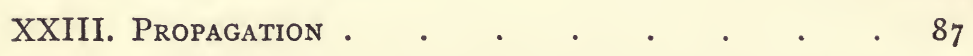

XXIV. Calendar of Operations in Apple and Pear

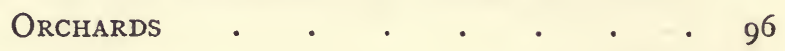

XXV. Apple CoOKery . . . . . . . 104

INDEX $\quad+\quad \cdot \quad \cdot \quad \cdot \quad \cdot \quad \cdot \quad \cdot$ II6 


\section{LIST OF ILLUSTRATIONS}

PLATE

I. Pear: Doyenné dU COMICE . . . Frontispiece

II. APPLE: JAMES GRIEVE PAG

III. Pears: Émile d'Heyst and Beurré Alexandre

LUCAS . . . . . . . . 26

IV. Apples: Cox's Pomona and Cox's Orange Pippin 42

V. Pear: Durondeau . . . . . . $\quad$. 58

VI. APPLE: LORD DERBY • . • • . $\quad$ • 74

VII. Pear: Pitmaston Duchess • . . . 90

VIII. Apple: Baumann's Red Reinette . . . . I02 
$\rightarrow$ 


\section{APPLES AND PEARS}

\section{PART I}

\section{CHAPTER I}

\section{HISTORICAL NOTES}

THERE is every reason to believe that the Roman generals during their stay in Britain introduced seeds of their native fruits. Some of the hardiest of these were capable of withstanding the rigours of our climate, and after the departure of the Romans it is assumed that these became "wildings," owing to want of knowledge on the part of the inhabitants of these islands. It is, however, recorded that there were fruit markets in London in the eleventh and twelfth centuries; and also that there were fruit gardens around the Cathedral at Canterbury; whilst the royal archives mention that Edward I. commanded "Peares" to be planted in his garden at Westminster. The numerous abbeys and schools of the monks may also be supposed to have kept alive the culture of fruits in these early days, but up to the time of Henry VIII. there appears not to have been any general cultivation of fruit, for we read that the dessert for the royal table and for the nobles was imported from the Continent. King Henry VIII.'s fruiterer, Harris, introduced 


\section{2 \\ PRESENT-DAY GARDENING}

Cherries, Plums, Pears and Apples; and he established orchards at Newington, East Kent-a district which to-day sends the finest cherries to London - and some thirty parishes followed his example.

From that time fruit-tree propagation was carried on, and fruit-growing was practised as an industry. Perhaps the British ambassadors to France, Belgium, and Holland tried to introduce such fruits as they esteemed; but there is little evidence of any considerable development until Queen Elizabeth's reign, when Thomas Tusser published his Hundred Good Points of Husbandry (1557). Thomas Hill published a work in $\mathrm{r}_{5} 63$ which was mainly a compilation from other sources. Shakespeare mentions such Apples as the Catshead, Codlin, Sops in Wine, and Russets in his plays. In 1572 Leonard Mascall's Booke of the Arte and maner howe to plant and graffe all Sortes of Trees was published, being translated from French works. In $\mathrm{I}_{596}$ Gerarde published his famous Herbal, in which he gives plates of the chief wild varieties of fruit and refers to what we call the garden sorts as "Manured." He figures the Choke and Crow Peares of the wild forms, and of the garden sorts, the "Burgamot," which resembles our Conseiller de la Cour; "The Bishops," a large fruit like Pitmaston Duchess; "The Katharine," like Winter Nelis; the "Royal," after Beurré Diel ; "Jenneting," apparently the Lammas; "St. James," after Doyenné d'Eté ; whilst "Winter Pear" is apparently our Catillac, the "Warden" of the Monasteries. But Gerarde incidentally states that a friend grew as many as three-score varieties, so that it is clear that by this time interest was being aroused.

In I6I3 Markham published a translation from the 
French of Libaut and Etienne's Maison Rustique. In I6I8 William Lawson's work, A New Orchard Garden, appeared, and in 1629 Parkinson's first edition of Paradisus was printed. He gives a few plates of the wild varieties of Pears and Apples, but in Apples he only names one which he calls "Manured" (renewed or improved)-the Holland Pippin, which is occasionally met with even to-day in Lincolnshire. The present writer had an old orchard which contained a tree of this variety; it was remarkable for its large and lovely pink and white flowers, but the fruit was inferior.

Ralph Austen's quaint volume $A$ Treatise of Fruit Trees and the Spiritual Use of a Garden of Fruits was published in 1653. He mentions that the Sultan of Turkey had Pear trees on the Quince stock potted up to decorate his palace. John Beale wrote a treatise in 1657 extolling The Hereford Orchards- a pattern for the whole of England, which no doubt laid the foundation of fruit culture in the Western Midlands. It may be mentioned here that the finest illustrated book on the subject yet published is the Hereford Pomona (1878-80), edited by Dr. Bull assisted by Dr. Robert Hogg. The plates are beautifully coloured, and the edition is a sumptuous work of five volumes. Evelyn's translation of Quintinye's The Compleat Gard'ner in 1693 had a profound influence on fruit-growing; it was copied from later by Loudon and Wise. Publications of a more or less popular nature were John Lawrence's Clergyman's Recreation (I7I4) and Switzer's Practical Fruit Gardener (1724). Philip Miller's well-known work maintained the interest in Pomology, till Batty Langley in $\mathbf{I} 720$ produced the first book that gave really good illustrations 


\section{PRESENT-DAY GARDENING}

of fruit. Thos. Hitt (I757), John Abercrombie ( 1767 ), and William Forsyth (I79I) still further added to the literature of fruit culture. In 1796 Thomas Andrew Knight published his work entitled a Treatise on the Culture of the Apple and Pear, and he raised some fine Pears, of which "Monarch," of first-class Bergamot flavour, ripening in February, is the only variety in cultivation; it is very liable to drop its fruit. Its keeping qualities render it valuable for those who have suitable fruit stores, as good Pears in February are scarce.

In I83I Ronalds published his Pyrus Malus Brentfordiensis, which contains well-executed plates of the best Apples of his time, with descriptive and cultural notes; some of these varieties are still valuable. Following his lead, the London and provincial nurserymen began to make a speciality of fruit-tree production, such names as Lee of Hammersmith, Osborn of Fulham, Wilmot and Chaundy of Lewisham, Dancer of Chiswick, Paul of Cheshunt, Garraway of Bristol, Glendinning of Chiswick, and Luccombe and Veitch of Exeter being amongst the trade pioneers. Thomas Andrew Knight of Worcester and Lord Scudamore of Holme Lacey, Hereford, succeeded in making their counties eminent for both cider and table fruits, whilst Braddick of Thames Ditton introduced many good varieties, including Marie Louise Pear. At the same time Devon and Somerset imported fruits from Brittany and laid the foundation of the cider industry. Most of the old orchards in these counties may date from this period, as many of the Pears are certainly $\mathrm{I}_{50}$ years old, yet the trees are as healthy and lofty as English Elms.

The middle of the nineteenth century marked a great 
and notable progress, and the dominating cultivators of this period were Thomas Rivers of Sawbridgeworth, J. R. Pearson of Chilwell, R. Smith of Worcester, Thomas Bunyard of Maidstone, and H. Lane of Berkhampstead. R. D. Blackmore at Teddington, and Dr. Lindley and Robert Thompson at the Chiswick Gardens of the Royal Horticultural Society, were introducing new varieties from the Continent; Thompson got together a large collection, many of which proved but second-rate in our climate. A valuable book on fruit was issued by the Royal Horticultural Society in 1853 , and this was the standard authority for some time. Dr. Hogg brought out his Fruit Manual in 1845, and the third edition, published in 1866 , was a book of $4 \mathrm{I} 4$ pages. From that date the culture of fruit for market sale, as distinguished from that grown for home consumption and cider, became a serious business. Meanwhile, Mr. Thomas Rivers and Mr. J. R. Pearson introduced from France the practice of cultivating Apples on the Paradise stock and Pears upon the Quince stock, and the cordon system of culture began to be practised in gardens, together with the growth of pot fruit-trees in orchard houses with but little or no artificial heat.

Mr. Rivers' treatises on the management of orchardhouse trees and the cultivation of pyramidal and bush trees in gardens gave the knowledge required for a stimulus to the fruit industry. The old saying "Plant Pears for your heirs" became inappropriate, as trees on the Quince stock began to bear in two or three years, and Apples on the Paradise stock were equally precocious. These "fancy" trees became very popular, but they did not oust the old-fashioned and profitable espalier trees. Better than 


\section{PRESENT-DAY GARDENING}

all was the fact that these fancy trees, if planted early, often produced fruit the first year of planting. Unfortunately, there were Paradise and Paradise stocks, and as the idea was French, many firms quite naturally purchased French Paradise stocks. This variety is a bad, short-lived stock, and, as proved by Barron at Chiswick, it often died even before it had been budded. Luckily, Mr. Rivers found among his seedlings two fine, surface-rooting Apples, which are to-day unsurpassed for working with choice Applesthe Nonsuch and the Broad-leaved Paradise. Trees upon these two stocks give promise of a life equal to the venerable standards of our orchards, and they are the only reliable stocks for the purpose of cordon, pyramidal, and bush trees. In the nurseries we have also a few grand standards on the Paradise; even these are safe in sheltered positions.

Mr. A. F. Barron carried on the work begun by Robert Thompson at the Chiswick Gardens; he made many valuable contributions to fruit culture, and the trials he carried out were most instructive. In some respects it may be said that the chief starting-point in hardy fruit culture was at the Fruit Conference held in the Chiswick Gardens in 1883 , when a much-wanted opportunity arose to correct the nomenclature, which was sadly defective in country districts. It served also to bring forward many littleknown fruits, and at the same time to indicate useless varieties which it was not worth while to grow when greatly improved sorts were available.

The Report of that Conference issued in I 884 furnished a valuable work of reference. The success of the Exhibition led to the holding of a Conference on Pears, and a General 


\section{CONFERENCES AND SHOWS}

Conference at Edinburgh; at both events the present author acted as an expert.

The palmy days of the Crystal Palace gave a great impetus to the culture of fruit, as liberal prizes were offered at the exhibitions. The trade collections were always an attraction, whilst their educational value, and the opportunities they afforded for comparison and inspection of new varieties, were much appreciated. On these shows being discontinued, the Royal Horticultural Society-whose reconstruction had introduced some practical men on the Council-saw its opportunity, and the Society's Autumn fruit shows have since done a vast amount of good. They have brought together such grand examples of fruit as would have been impossible thirty years ago, when the culture of the trees was less generous, the system of pruning less perfect, and when the planting of Pears upon Quince stocks and Apples upon the Paradise stock was unknown.

Market-growers, however, were slow to move, and it is only within the last twelve or fifteen years that such dwarf trees have been planted by the thousand; nevertheless, the effect can be seen already in the greatly improved quality of the fruit in the chief markets. Another factor arose about the year 1883 -I may say by accident. The great orchards in the principal fruit counties, till that period, were never manured, beyond that which resulted from the keeping of cattle or sheep in them; and even in these cases the animals were not often fed with corn or oilcake, so that the trees received little benefit. But in 1883 the main drainage of London was being carried out; millions of bricks were sent from the Sittingbourne district in barges. Now, the London scavengers were very glad to sell their 


\section{PRESENT-DAY GARDENING}

manure at a low price to get rid of it in order to satisfy the sanitary authorities, and thus the barges, instead of returning empty, carried freights of manure. The arable fields having been fertilised in the winter months, the orchards came in for a share in the summer time. The effect was magical, and growers were found saying, "Why did we not think of this before?" Not only were there increased crops, but a marked superiority in quality. Higher prices were obtained for the fruits, and an impetus was given to the laying down of orchards, which of late years bas been further stimulated by the fact that the culture of Hops trequently failed to yield a profit, and the heavily manured hop-lands were found to be capable of growing orchard trees for several years without manure.

Again, the owners of large gardens, and even villa residents, began to take more interest in their fruit supply, recognising the superior quality of freshly-gathered fruit; and whereas in former days trees on free stocks produced more leaves and wood than fruit, the dwarf trees on Paradise and Quince stocks made it possible for planters to grow many varieties in a small space and to get early returns.

So much for the history of fruit culture. I find the first catalogue issued by my firm is dated 1827 . It was printed in London, and I believe that my father worked jointly with the late William Masters, nurseryman, of Canterbury in getting out this catalogue, to save expense in printing, which in those days was a serious matter.

I may be excused in referring to a personal matter, but as a boy of from ten to twelve years I used to enjoy assisting in gathering the fruit from our orchard, founded by my grandfather in 1796 , and thus early obtained a practical in- 


\section{DERIVATION OF TERMS}

sight into varieties and their manners and keeping qualities, as I stored them for use. Later on I was permitted to plant up the old orchard, provided I helped in the planting - a wise plan on my father's part-and this gave me a further insight into the work, and stimulated me to master the subject quite early in life ; while, when we moved our nurseries to Allington in 1869, I cut every graft myself, and thus was sure of starting there with a true stock. I may here very freely acknowledge the kind help and assistance I received from many good friends in the trade, and scores of other first-rate fruit-growers who have passed away.

Before passing to more practical matters, it may be of interest to explain the derivation of certain terms used by fruit-growers. Taking Apples first, the word "Pippin" is derived from the French pepin, "a seed," or, as we should call it, "seedling." The term Pippin is generally given to varieties that produce rather small fruits with long stalks.

The "Pearmain," or "Paremain," of the old writers is a corruption of Pyrus magnus (Great Pear-shaped). It is applied to conical fruits resembling some of the obtuseshaped Pears.

The "Reinette" (French) or Rennet (English) is from the Latin renatus, meaning " renewed, improved, or regenerated." This term may have been first applied to such varieties as were raised from seed and proved to give better fruit than the parent variety.

The word "seedling" is now often omitted from catalogues, and as all new varieties were raised originally from seed, it is not needed.

In relation to Pears, "Bergamot" is applied to those 


\section{IO PRESENT-DAY GARDENING}

fruits that have a rich aroma, and this race have generally flattish, globular fruits.

"Beurre" is French for "butter." A buttery Pear is one that melts in the mouth ; the flesh being of fine texture, and without grit at the core. "Fondante" again means "melting."

"Doyenné" is probably meant to signify "very superior," or "above average merit"; some translate it as "the Dean's," which the French word stands for. I am informed by Mr. Brotherston that in the seventeenth century Doyenné was translated Denny and The Dean.

"Colmar" is a term given to varieties which originated in that French district.

\section{CHAPTER II \\ PURCHASE OF TREES AND CHOICE OF POSITIONS}

Amateurs should avoid buying at auction sales, as they have no guarantee that the varieties are even true to name. The catalogues published by the leading fruit nurserymen give all particulars, and if the uninformed amateur is wise he will place himself in their hands. Buyers may wish for varieties that canker, or are very poor bearers; or they may be misled by handsome fruits exposed in shops under wrong names; or they may choose sorts that are years before they become profitable, unless they obtain proper information. The special lists of Apples and Pears given in this volume may be accepted by fruit-growers and amateurs alike as absolutely reliable. 


\section{ARCHES AND PERGOLAS II}

It must be remembered that some varieties grow much stronger than others which take longer to form trees, so that buyers must not expect all the trees to be even in size and vigour.

Trees are sent from the nurseries with labels which are only capable of lasting a very few years, therefore, if it is desired to keep the names, new labels are required, and those known as Pinches' Indelible Zinc are recommended. In attaching these latter with wire, they should not be fastened to the tree, or the branches will swell and the wire cut in and injure the wood; the wire should be attached to a stake, or the wall, as the case needs.

In selecting positions for Apples and Pears it is well to reject situations exposed to the north and east, and some protection may even be needed from westerly gales until the trees are sufficiently grown to protect each other. It is not a good plan to plant near streams or lakes, as spring frosts do most damage in such positions. In gardens the walls and shrubberies form good protections for young fruit-trees.

Arches and Pergolas.-Pears and Apples trained on arches and pergolas are very ornamental when in flower, and the fruit produced is generally well coloured. In separate arches the same variety should be planted on each side, and in a continuous "pleached alley" cordons may be planted at $2 \frac{1}{2}$ feet apart, about six of a kind on each side. A space of ground 3 feet wide should be dug out 2 feet deep, and the trees planted in the centre of the trench. Some pretty annual Howers of low growth could be then grown on the soil of the trench, while an inner line of Daffodils will produce a charming effect in spring. 


\section{I2 PRESENT-DAY GARDENING}

When the trees crop, give stimulants as recommended later on-but do not manure those trees that are without fruit. The trees can be trained to arch over as they grow long enough for the purpose.

\section{VARIETIES FOR PARTICULAR ASPECTS}

Apples for walls or fences should only be planted in aspects facing east or west, as in hot, dry positions they are specially subject to red spider. For exhibition purposes Gascoyne's Scarlet and Peasgood's Nonsuch are indispensable Apples. Lane's Prince Albert, Stirling Castle, and Warner's King are also kitchen sorts that do well in these positions; and amongst dessert varieties there are Allington Pippin, James Grieve, Lady Sudeley, American Mother, Roundway Magnum Bonum, and Cox's Pomona. If late varieties are desired, Claygate Pearmain, Sturmer Pippin, Hormead's Pearmain, and Sanspareil will be found good and reliable sorts. Apples are successfully grown on south and west walls in the northern counties.

Early Pears succeed best on positions facing to the east. They ripen too fast on the south or west walls. Souvenir du Congrés, Marguerite Marillat, and Beurré d'Amanlis are recommended. For positions facing west select Pitmaston Duchess, Louise Bonne of Jersey, Durondeau, Beurré Hardy, and Beurré Superfin. For a south aspect, Doyenné du Comice, Emile d'Heyst, Easter Beurré, and the delicious small Pear Winter Nelis; and for use after Christmas, Nouvelle Fulvie and Le Lectier. Catillac and Bellissime d'Hiver, two good stewing Pears, may be 
Apple: James Grieve

(An excellent dessert Apple of easy cultivation. Ripens in October) 



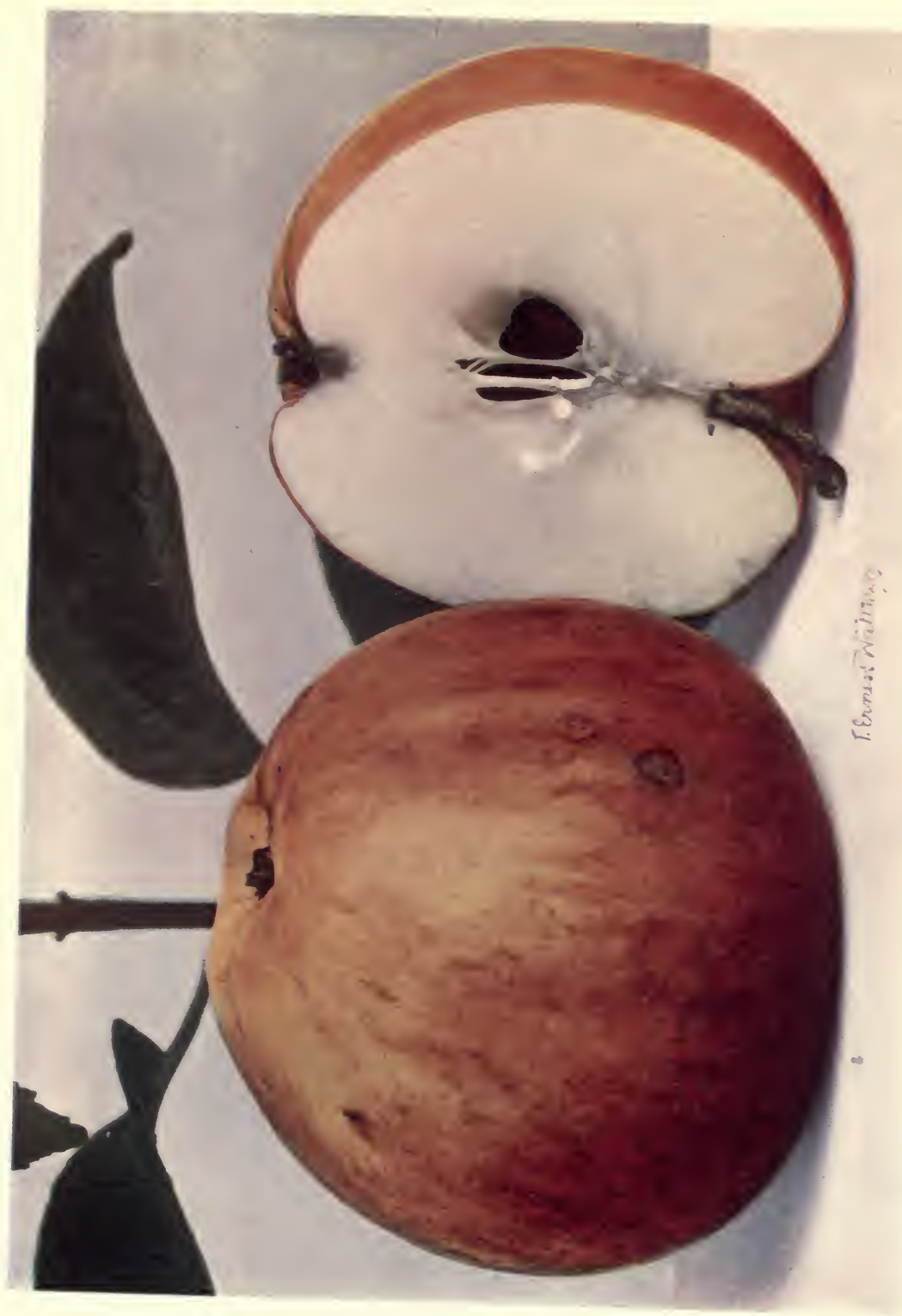




\section{PREPARATION OF THE SOIL I 5}

grown on a north aspect, and for a late supply of the popular variety Williams' Bon Chrétien this aspect is also suitable.

Espalier trees can be planted on the sides of the garden paths at I $_{5}$ feet apart, or be used as a fence to shut off the lawn or flower-garden from the vegetable quarters. Pyramids and bushes can be either planted 8 feet apart at the sides of the paths, or a quarter can be given them across the borders. Both pyramids and bushes should be placed at least 6 feet from the paths to allow for extension, but espaliers, being flat trees, need only be set back $I \frac{1}{2}$ or 2 feet from the paths. Cordons can be planted each side of the paths, set back $I \frac{1}{2}$ feet, at 2 or 3 feet from tree to tree. Standards require to be planted from I 5 to 20 feet apart.

\section{CHAPTER III}

\section{PREPARATION OF THE SOIL AND PLANTING}

MosT fruit-trees prefer a well-drained, deep-rooting medium, and for that reason heavy, sticky clay land requires to be drained and tempered by exposure to the winter frosts. The soil should have incorporated with it long strawy manure, ashes, burnt earth, and lime. It can then be planted with Apples and Pears, the latter preferably on Quince stocks, as the Quince is a water-loving tree; and the Apples should be worked on the Paradise stock. 


\section{I6 PRESENT-DAY GARDENING}

Where the land is a good, friable loam, turning up the soil to sweeten a month or two before planting is still advisable; but such land is generally rich enough without extra manure, which, if used at planting, often leads to excessively sappy growth, canker, and unfruitfulness.

In sandy ground which is deficient in vegetable humus, it is advisable to add some well-rotted manure, such as may be got from an old hotbed; and if very hot and dry, the addition of clay and porous stones, which will store moisture for the roots in summer, is to be recommended.

In stony land, a hole, 3 feet over and 2 feet deep, should be made, and if the soil is at all brashy or hassocky, fresh loam should be used in planting.

Soils intermediate between the above can be treated similarly, but none should be over-manured.

In wet soils or after heavy rains it is not advisable to dig out the holes for trees before they arrive, as they will often become full of water, but on light soils it saves time and allows trees to be quickly placed when the holes are prepared beforehand.

Apples grow late in the season, and they do not often shed their leaves until the middle of November, but Pears are earlier. After years of experience, we are forced to the conclusion that, when the land is in good condition and not too wet, planting can be done from November ro to March I5 with perfect safety; but it should not be carried on during frosty weather.

It is very bad practice to plant too deeply, but it is important that Apples on the Paradise and Pears on the Quince stock should have the junction of the stock and 
scion 3 inches below the surface, to prevent the scion overgrowing (strangling) the stock.

The term "stock" is applied to the tree on which the improved variety as a "scion" is propagated by budding or grafting (see p. 92). Grafting is performed in the spring and budding in the summer season. The best propagators prefer budding, as the wound made on the removal of the stock or snag, left above the union of stock and scion, grows over more quickly than where a tree is grafted, and the wound is often not observable in budded trees two years old.

For planting garden trees the holes need not be deeper than $I \frac{1}{2}$ feet, but the soil below this depth should be broken up with a pick or fork for another 9 inches, and the base of each hole may be opened out a little round the lower edges.

Before placing the tree, the centre of the hole should be raised 6 inches above the level, in order to prevent water lying at the root. The tree having been previously prepared by cutting back its lower anchor roots and by shortening the straggling roots by 3 or 4 inches, taking care to cut from the under side, the tree is then placed in the hole and some fine soil thrown over the roots, which must be worked in carefully with the fingers between the roots. The tree is then lifted 6 inches and slightly shaken to release the upper roots from the soil. These are again spread out and more soil added until the hole is three parts filled in, when the tree should be trodden very firmly without breaking the roots. It is necessary to plant as firmly as possible, then fill up the hole with fine soil, having regard to the advice given 


\section{8 PRESENT-DAY GARDENING}

above as to placing the junction of stock and scion 3 inches below the level. In heavy clay soils it is desirable to plant only 9 inches deep, and earth up the uppermost roots above the ground level.

\section{CHAPTER IV}

\section{PRUNING}

Although I am often attacked for advocating that all Apples and Pears should be allowed a year's growth before pruning, I still think that this is the best plan. Dwarf trees carefully planted in November or December, provided the season is favourable, may be pruned the following April after planting, but for standard Apple and Pear trees it is most important to let them grow a year before pruning. Stone fruits produce more fibrous roots, and can be pruned the first year if well planted.

In pruning regard must be had to the form of tree desired. If a standard, aim at getting a well-balanced head, preferably 3-5 shoots as a start, and cut these back after the first summer's growth to 6 inches, always pruning to a growth bud pointing outwards. From this pruning several shoots will issue, and those in the centre of the tree can be cut back (spurred) to four leaves about the first week in August, leaving at the next winter pruning two or three leading shoots to extend the head; these leaders may be allowed to retain a foot length of new growth annually until the proper shaped head is produced, carrying on the spur pruning of inner shoots yearly, in August or September. 
Summer pruning is often done too early for appearance' sake; but this practice induces secondary growth, which is not desirable.

In respect to pyramidal or bush trees, these, if grown on the Paradise stock and carefully planted before Christmas, may be cut back in February as I have stated. Should the pyramidal form be desired, a stake should be used to train the central stem, and the side lower shoots may be cut to four or five eyes, leaving the end bud pointing outwards. In the following August these pyramids, as well as bush or basin-shaped trees, may be spurred as advised for standards.

In forming basin-shaped trees, it may be needful to train the shoots to balance equally

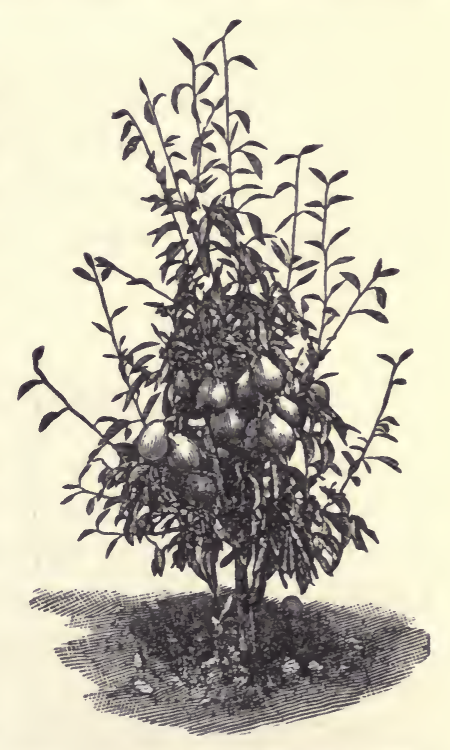

Fig. I. - Pyramidal Pear Tree like the spokes of a wheel, by tying them down to a rim of wire which can be stretched on five low stakes, and pruning them as directed for pyramids in order to get extension growths, spurring the inner shoots in August, and allowing the main shoots to extend from 12 to 18 inches each year.

Single cordons should be trained upright for a few years until they reach the top of the wall or support, when they may be lifted for root-pruning and be planted 


\section{PRESENT-DAY GARDENING}

obliquely to gain another foot or two for extension. Cordons may make a few gross side shoots in summer, and these can be cut back to four eyes in August; but I do not advise the leading shoot to be shortened the first year, as that operation sometimes checks growth and leads to the formation of fruit buds which make it difficult to obtain a growth lead in the following year. But after a summer's growth the lead may be shortened to cause fruit buds to form and produce new side spurs. Double cordons for edgings can be treated in the same manner.

\section{ESPALIER TREES}

During the first year espalier trees should be left to grow as they like, but if the lateral arms throw out any wood growths which may tend to weaken the leaders, cut these back to four leaves in August, not earlier, and the following winter the extension laterals, which may have formed some fruit buds at their base, must be cut in to a growth bud for producing new wood for extension; such growths must be trained laterally as they form. It is important in pruning the laterals or side branches that the upper shoots should be cut back more severely than the lower shoots-say, like the letter A-otherwise the upper arms may prevent the lower ones from developing.

If espaliers of two tiers of branches are planted, and the intention is to have five tiers, the way to get these is to cut back the central leader to ${ }_{5} 5$ inches each year in February. From the end thus left on the tree three or four shoots arise; the side ones in the best positions are trained to the 
right and left, and the central shoot is tied to an upright stick, similar pruning and training being repeated in the following February, until the desired tiers of branches are obtained, when the central shoot is cut clean away. In

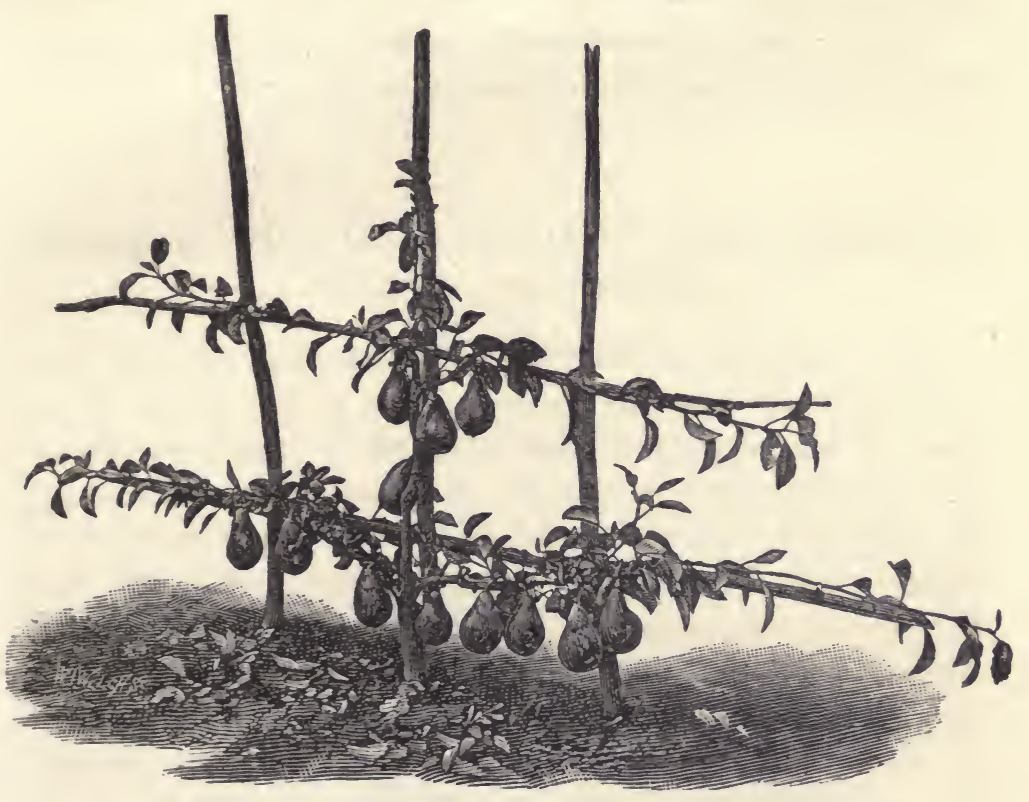

Fig. 2. - Espalier Pear Tree with two Tiers of Branches (From the Gardeners' Chronicle.)

spurring the lateral branches in summer, it is well to commence a fortnight earlier on those in the centre of the tree, so as to cause the sap to be diverted into the extension growths, because these central shoots are stronger and may weaken the leaders if allowed to develop unchecked. 


\section{PRESENT-DAY GARDENING}

A fruit bud is a knobby short growth, like the end of a vesuvian match, whilst a growth bud lies close at the base of the leaf and is pointed in shape.

A spur is a collection of fruit buds forming irregularly on the main branches.

The pruning of side branches is described in the following notes on horizontal and fan-trained trees.

\section{HORIZONTALLY TRAINED AND FAN-TRAINED TREES ON WALLS}

The pruning of these is similar to that advised for espaliers in the open in regard to extension. A mistake is often made in laying in the side branches too closely together; I 2-I 5 inches apart is not too wide, as, when spurs form too thickly, it is not unusual to find trees that have been covered with blossom fail to set an even crop, the tree having become exhausted in the flowering. When spurs are ten years old they should be thinned out to prevent this loss. As to the side branches, the points from time to time must be cut back to secure balanced growth on each side, and if any strong shoots form on these branches they should be reduced to four leaves in August. From time to time the old nails and shreds should be exarnined to see that they do not cut into the growths, renewing the shreds when this is necessary, and allowing plenty of space for the swelling of the wood. Some Pears and Apples form fruit buds more readily than others, but if any buds remain dormant they may sometimes be started by making a cut through the bark behind or 
below the bud, and thus furnish a shoot and prevent an unsightly gap.

Summer-pruning can be commenced early in August in the warmer counties, but it should be completed in that month. I have said already that if the pruning is done earlier secondary growths form, and these weaken the tree and keep the sap active when rest is needed. If, however, secondary shoots are made, rub them out in September.

\section{CHAPTER V}

\section{ROOT-PRUNING}

THIS is a very important point in the culture of fruit. It frequently happens that after the second year of planting, through the soil being rich or fresh, newly planted trees make gross growth, and in order to keep them in shape very severe pruning is carried out; but this only makes the trees produce still stronger wood, and the formation of fruit buds is thus arrested.

In these cases a systematic root-pruning is the only desirable way of bringing the tree into a fertile condition. At the end of October, or as soon as possible afterwards, open a trench 3 feet from the main stem and shorten any roots of strong growth that may be found, pulling out the ends, not leaving them in the soil. If, however, but few are found, it is the tap root which must be severed by working well under the tree. After doing all the root. 


\section{PRESENT-DAY GARDENING}

cutting necessary, fill up the hole carefully, spreading out the fibrous roots as the work proceeds, and make the soil very firm. Do not add any manure, but introduce some fresh turfy loam in place of the old soil. The strongest roots are usually found opposite the gross growths. In that case, only one side need be operated upon. With large trees of considerable age, it is well to root-prune one side one autumn and the other side in the following season, for if this work is too severely carried out at one time, the tree may die, or rest for a year or two, making only a few small leaves. In the case of old wall trees where the spurs are very numerous, it may be advisable to remove some of the pairs of lateral or side branches, and to thin the spurs out freely.

It is considered that the tap or anchor roots favour the growth of shoots and branches, and the upper and more fibrous roots and rootlets favour the growth of fruit buds.

In no case, however, should standard trees be rootpruned, as their roots when shortened have less grip of the soil, and this may cause the trees to blow over in a gale. Large pyramids or bushes should be very severely pruned; even whole branches may be removed with good effect, before the trees are root-pruned. This is done because the transpiration from a mass of foliage after the roots have been reduced may be more than the tree can afford until new roots have formed. 


\title{
PLATE III
}

\author{
PeAR: Émile D'Heyst \\ (Ripens in October and November.)
}

Pear: Beurré Alexandre lucas

(Has a flavour resembling Louise Bonne of Jersey. November.) 



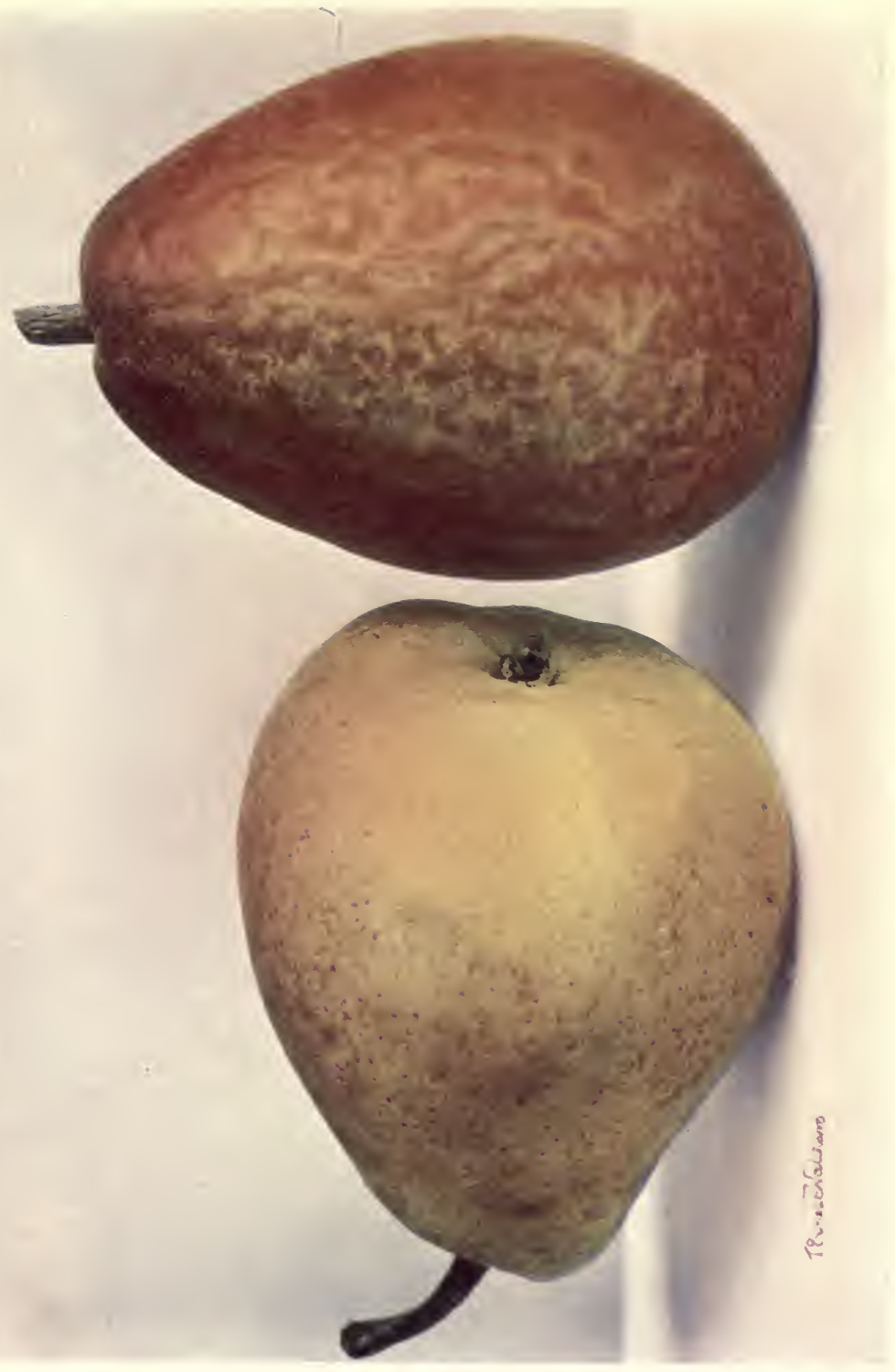


- 


\section{CHAPTER VI}

\section{SELECT LISTS OF APPLES}

WE will now consider the best varieties for small gardens, omitting those strong growers which require years to reach a profitable bearing stage, as Blenheim Pippin, Bramley's Seedling, and Warner's King, also those that are apt to canker in the boughs, as Dumelow's Seedling (Wellington), King of the Pippins, Ribston Pippin, and Tower of Glamis.

First a list of six will be given for a villa garden, to be grown as pyramids or bushes. The dessert varieties should be Mr. Gladstone for use in August, James Grieve (October), Allington Pippin (November to February) ; and for cooking, Early Victoria (August to September), Golden Spire (October), and Lane's Prince Albert (November to February). These are compact growers, and they seldom fail to bear well. Should a larger selection be desired, add Worcester Pearmain (September), Lady Sudeley (September to October), Cox's Orange Pippin (November to January), and Baumann's Red Winter Reinette (February). For cooking, Stirling Castle (October), Lord Derby (November to December), and Newton Wonder (January to March). All these varieties when grown upon the Paradise stock give good results.

The following descriptions will be useful :-

The variety $M r$. Gladstone sometimes ripens in midJuly. The fruits have a nice flavour, but they should be 


\section{PRESENT-DAY GARDENING}

eaten direct from the tree without keeping. Colour, red, streaked with crimson on the sunny side; fruits small. The tree forms a slightly weeping specimen.

James Grieve is a constant bearer, and the flavour is brisk rather than rich. Colour, yellow with red in patches. Medium size. The growth of the tree is very compact.

Allington Pippin is a robust grower which bears freely. The flavour in a warm season is first-class. Colour, primrose, with red cheek or flushed with red. Rather large size.

Baumann's Red Winter Reinette.-It has been thought desirable to include this variety because it is a constant bearer, succeeding well in town gardens. The fruits are flat in shape, good for table, and they can be used for baking.

Golden Spire grows upright, and is most prolific. The fruits are of clear yellow, medium size, and they cook well.

Early Victoria is an abundant bearer and a free, healthy grower. It is about the first Codlin to ripen. Colour, deep primrose. Medium size.

Lane's Prince Albert.-The growth is rather pendent, and the tree a great bearer. The fruits are large, and they keep sound till the last. Colour, greenish yellow, sometimes striped with scarlet. Large size.

Worcester Pearmain.-A pretty, scarlet fruit of good flavour when freshly gathered. Medium size. The habit of growth is upright.

Lady Sudeley.-Very handsome, striped, or flushed crimson. Rich flavour and aroma. Should be eaten direct from the tree. Above medium size. Growth, weeping.

Cox's Orange Pippin.-The finest flavoured dessert Apple, but very subject to spot and canker. This is the reason 
it is not included in the first six, but when well grown it has no equal. Colour, golden with bronzy red. Must not be planted in cold or clay soils.

Stirling Castle.-A perfect kitchen Apple, large in size, cropping so freely as to limit its growth. Weeping. Colour of fruit, greenish yellow.

Lord Derby.-Growth, upright. A regular bearer, giving fine, large, golden fruits. They often require thinning freely.

Newton Wonder.-A fine, late fruit which is preferable to Bramley's Seedling for small gardens, as it comes into bearing in a young state, and has cooking qualities equal to Dumelow's Seedling.

All the varieties named above succeed as standard trees where there is space for development, but they also make excellent espaliers or cordons.

\section{SELECTIONS FOR LARGER GARDENS}

In larger gardens the following additional varieties may be cultivated with advantage :-

Dessert Fruits: Summer Golden Pippin or Ingestre.A small yellow fruit of brisk flavour, and appreciated by many. It ripens in September. The tree is weeping as a standard, and it bears abundantly.

Ben's Red.-Very free bearer in any form, and more reliable than Quarrenden. Brisk, good flavour. (September to October.)

Margil.-A small fruit of first-class flavour. Habit of growth, compact. (November.) 


\section{PRESENT-DAY GARDENING}

St. Edmund's._-The earliest Russet, and possessing very rich flavour. Habit of growth, compact. (October.)

Ross Nonpareil.-A pretty fruit of rich flavour. The tree is a good bearer. (October to November.)

American Mother. - The richest flavoured fruit for October. Habit of growth, compact.

Cox's Pomona.-Soft flesh of pleasant flavour. Rich colour. (October to December.)

Norman's Pippin.-Very rich flavour. Habit of growth, compact; a moderate bearer. (December.)

Hormead Pearmain.-The fruits keep sound until April, and are then of dessert quality. The tree is a compact grower and sure bearer. (January to March.)

Roundway Magnum Bonum.-Fruit very large, of delicious aromatic flavour. The author considers this the finest of dessert Apples. Growth, spreading. Does well as standard or bush. Bears moderately, and is worthy of a west wall. (December to January.)

We do not enumerate many late-ripening Apples, as they require a suitable store to keep them in plump condition, but those who require more of this type should consult the trade catalogues.

Cooking Apples: White Transparent.-A beautiful, primrose-coloured fruit. The first to ripen. Good also for dessert. The tree is of free growth and an abundant cropper. (August and September.)

Grenadier.-The finest Codlin. Large. The tree is a great bearer in any form. (September.)

Lord Grosvenor.-Habit of growth, compact ; very prolific. Requires thinning as it bears in clusters. Excellent cooker. (September and October.) 
Bismarck.-Fruits green, flushed with crimson, and possessing a sharp flavour. The tree is a great bearer. December.

Edward VII.-Growth free. A fine late cooking Apple. (January.)

Annie Elizabeth.-Growth, upright. An improved Wellington, keeping good till March.

Alfriston.-Habit of growth, compact. A fine old green variety, keeping till May.

Although it is necessary to limit the select Apples to a few varieties for villa gardens or private use, there are some fifty excellent sorts. For example, the old Ribston Pippin is only omitted because the tree is so apt to canker.

\section{NEWER DESSERT APPLES}

The following are a few of the newer dessert or littleknown Apples that appear very promising :-

Langley Pippin (August).

Rival (October to November).

St. Everard. A seedling from

Cox's Orange Pippin, of delicious flavour (October).

$\mathrm{Wm}$. Crump, of same origin as

St. Everard (November).
Christmas Pearmain. King of Tompkins County (November to December).

Houblon. A seedling from Cox's

Orange Pippin (January).

Lord Hindlip (February).

Sanspareil (February). 


\section{PRESENT-DAY GARDENING}

\section{RECENTLY INTRODUCED COOKING APPLES}

Rev. W. Wilks. Large and prolific (October to November). Hector Macdonald and Seedlings from Lane's Prince Albert (DeEncore.

Hambling's Seedling (April).

Byford Wonder (March).

Norfolk Beauty (October). Large, and does not fall in cooking.

\section{LARGE HANDSOME APPLES FOR EXHIBITION PURPOSES}

Grenadier.

Emperor Alexander.

Norfolk Beauty.

Warner's King.

Lord Derby.

Peasgood's Nonsuch.

Golden Noble.

\begin{tabular}{|l|l} 
Blenheim Pippin. & *Baron Wolseley. \\
Royal Jubilee. & Newton Wonder. \\
*Mere de Menage. & Edward VII. \\
Gloria Mundi. & Sandringham. \\
Lane's Prince Albert. & Hambling's Seedling. \\
Byford Wonder. & Annie Elizabeth. \\
Bramley's Seedling. &
\end{tabular}

Those marked * are rich red or crimson. Peasgood's Nonsuch is the handsomest Apple grown, but it is not given in the select lists because it cankers badly and is liable to cast its fruits before they are mature.

\section{DESSERT APPLES FOR EXHIBITION IN AUGUST OR SEPTEMBER}

Mr. Gladstone.

Beauty of Bath.

Worcester Pearmain. den. Lady Sudeley.

Ben's Red. Devonshire Quarren- James Grieve. 


\section{DESSERT APPLES FOR OCTOBER AND LATER}

*Wealthy.

King of the Pippins.

*St. Edmund's Russet.

*Calville Rouge Précoce.

$\dagger$ Ribston Pippin.

*Cox's Orange Pippin.

†Ross Nonpareil.

†Christmas Pearmain.

†Claygate Pearmain.

*Baumann's Red Winter Reinette.

*Barnack Beauty.

*American Mother.
*Allington Pippin.

†Egremont Russet.

Rival.

*Adams's Pearmain.

†Blenheim Pippin (select the smaller fruits).

†Roundway Magnum Bonum (small fruits).

*Gascoyne's Scarlet Seedling.

* King of Tompkins County.

†The Houblon.

†Duke of Devonshire.

* These are the best for beauty and quality. † These have good quality but are not so attractive in colour. Very late sorts are omitted, as Apple shows are generally discontinued after December.

In selecting exhibition fruits, choose those with clean, unspotted skins of bright colour. They must be of even size and no extra large fruits should be staged.

The friendly rivalry among small growers at local exhibitions is a pleasant feature of country life. It is only by seeing what others can do that general improvement in cultivation can be stimulated. 


\section{PRESENT-DAY GARDENING}

\section{SELECTIONS FOR THE NORTHERN COUNTIES AND SCOTLAND}

In Apples it is naturally the early varieties that succeed best in the North. The thirteen sorts described on pages 27,28 , and 29 are suitable, and to these may be added the seventeen varieties recommended for larger gardens. Cox's Orange Pippin and Roundway Magnum Bonum should be grown upon south or west walls. The following sorts also will generally do well :-

Ecklinville Seedling(September). Bramley's Seedling (November to March).

Cellini Pippin (September). Hambling's Seedling (March). *Irish Peach (September). *Kerry Pippin (August and September).
*King of the Pippins (October to November).

Peasgood's Nonsuch, on wall (November).

Potts's Seedling (September).

*Ribston Pippin, on wall (October to December).

*Galloway Pippin (March).

Those marked * are for dessert, the others being for kitchen use.

In the southern, eastern, and western counties, and in Ireland, the general lists can be depended upon, and for wind-swept seaside districts the six close growers recommended for villa gardens are most suitable. 


\section{CHAPTER VII}

\section{APPLES AND PEARS FOR ORCHARD HOUSES}

EVEN in favoured localities, the best cultivators are sometimes baffled by violent changes of climate, which destroy the crops of Pears on outside walls. After reviewing such trees in a severe spring, it is refreshing to open the doors of the cool orchard houses, and witness health, vigour, and beauty of the foliage, with heavy crops of fruit on the pot trees, and thousands of thinnings on the ground, removed by the gardener at the first general oversight. If this is so in the South, how much more could be said in favour of orchard houses in the colder Midlands and the North? As a hobby, pot trees are most interesting and delightful, first in their perfect blossom, then the gradual development of the fruit, and the succession of perfectly ripened examples of Plums, Peaches, Nectarines, Apples, and Pears-a season reaching from the month of June until November, when the houses can be cleared for Chrysanthenums, to be refilled again after Christmas with the pot trees.

Pot-grown trees insure a crop in any district, or when bad weather obtains at the time of flowering, and it is the best method of growing fruit of the largest size and of striking appearance, with fully developed colour and flavour.

The orchard house need not be an expensive structure. 


\section{PRESENT-DAY GARDENING}

It should be erected in a position where it will be fully exposed to the sun during the whole day. The structure may be entirely of wood, the sides being secured by posts extending 5 feet out of the ground at 6 feet apart, and the span roof supported by uprights in the centre. These uprights should be galvanised 2-inch hollow columns, with a cross slot at the top to take the pitch board and keep it in position, and the feet should be set in concrete. The feet of these upright posts should be about 8 inches square, flat, and a firm foundation should be made on a flat stone or bricks to prevent sinking, on which the concrete should fix the posts.

The house should be as large as space permits, as the temperature is much easier to control in a house of some extent. It should have a wide door at each end to admit a barrow or hand-barrow, and the triangular portion over the door should be made to open for ventilation. Means of ventilation should be also provided all round at every other opening between the posts.

A house 50 feet long and 20 feet wide is a useful size, and there should be an oblong bed in the centre, 8 feet wide, bordered on each side by a path 3 feet wide. This will leave an outside border of 3 feet all round, and would accommodate, say, forty pot trees set at first at 4 feet apart-to be thinned out later when they have made growth.

On each side of the path, at 6 feet apart, slight $(2 \times 2)$ wooden uprights should be fixed to the rafters, alternately, so that they run zigzag. On these uprights choice Pears can be trained as cordons, and if desired they may be allowed to extend and arch over the path, and also the 


\section{PEARS FOR HOUSE CORDONS 37}

central bed, on wires placed for the purpose 2 feet from the roof. These cordons are exquisite when in flower, and the fruit produced is of superb quality and size. The best Pears for this purpose are :-

Louise Bonne of Jersey (September).

Marguerite Marillat (September).

Durondeau (October).

Fondante d'Automne (October).

Pitmaston Duchess (October).
Doyenné du Comice (October and November).

Beurré Diel (November).

Duchess d'Angoulême (November).

and for a later supply :-

Beurré Alex. Lucas. | Duchess de Bordeaux.|Santa Claus.

Josephine de Malines. Doyenné d'Alençon. The Blickling.

Easter Beurré.

Le Lectier.

Olivier des Serres.

Nouvelle Fulvie.

Pears so grown do not ripen much earlier than those grown in the open.

The rafters need not be very stout, say $3 \times 2$, and they should be placed I foot apart; these can be purchased ready for use, as well as eave boards, plates, and pitch boards. The ventilating side shutters can be made of match-board. They should open outwards, and in fine weather may fall to the ground. A little chain and hooks should be fastened to each one in the centre for the purpose of regulating the admission of air in cooler weather.

As water is an important element, there should be guttering round the house to catch the rain-water from the roof, and this should fall to inside tanks at opposite ends, to save labour in watering. These tanks should be in 


\section{$3^{8}$ PRESENT-DAY GARDENING}

the corners, and can be partly covered over, so that the tops can be used to stand pots on, but space must be left for dipping cans and buckets.

Top ventilation is very important, and should be provided by lights to lift up by a cord from inside at every fourth rafter; the ventilating lights being placed on alternate sides of the upper part of the rafters, so that they may often be open on the side opposite the direction of the wind when there is too much force in the wind to allow of the lower opening being used; and, again, the ventilators over the doors may in other cases be open when it is not advisable to open the roof ventilators. Circulation of the air is desirable, because pure air is essential to good growth.

The structure being now built and glazed in, is ready for the introduction of pot trees. The earth should be taken out 6 inches or more deep and a good foundation of clinkers put in, say 3 inches, and on this place 3 inches of finely-sifted cinders. This will prevent worms entering the holes at the base of the pots. Of course, where the cordon Pears are placed on the uprights-and central supports may also be filled with cordons-the soil must not be removed for a space of 2 feet across. The shorter pot trees are then set at the sides and the taller ones in the central bed. Some gardeners sink the pot halfway in the border, but we do not find any advantage in this; neither do we allow the roots to get through at the base of the pots ; the advantage of having the pots free is that the house can be cleared in time to bring in pot Chrysanthemums to flower early, and thus the house is utilised for two purposes. 


\section{APPLES FOR POT CULTURE 39}

Again, in the winter the trees can be set quite close together, and the house be used to shelter such plants as Agapanthus, Pot Figs, Bays, and other trees in tubs.

Although primarily the house is intended for Apples and Pears, Peaches, Nectarines, Plums, and Greengages can be grown in it as well, provided the kinds are kept together, as Apples and Pears require less syringing than the others.

In addition to the cordon Pears named already, the following varieties are very fertile when grown in pots :-

Emile d'Heyst (November).

Winter Nelis (December).

Fondante de Thirriot (November).
Conference (October). Marie Louise (November). Souvenir du Congrés (September).

\section{APPLES FOR POT CULTURE}

The most showy Apples for pots are :-

Lady Sudeley (August).

Ben's Red (September).

Cox's Pomona (October).
Peasgood's Nonsuch (October).

Emperor Alexander (October).

Gascoyne's Scarlet (November).

For high dessert quality select the following varieties :Allington Pippin (November to King of Tompkins County (NoJanuary).

American Mother (October).

Rival (November).

Cox's Orange Pippin (November to January).

vember and December).

Ribston Pippin (October to January).

Reinette du Canada (December).

Add for late-keeping dessert fruits :-

Sturmer Pippin. Allen's Everlasting.
Adams's Pearmain.

King's Acre Pippin. 


\section{PRESENT-DAY GARDENING}

The trees should be pruned and repotted before they are brought into the house. In April they need looking over from time to time, to kill any caterpillars that may hatch out and be feeding on the young leaves or flowerbuds before the blossoms open. As soon as the flowerbuds expand, all possible air should be given on fine days, and the atmosphere should be kept dry.

In order to keep the house on the dry side during flowering, give the pots a good soaking a week before the trees begin to flower, and then withhold water.

Should several dull days succeed each other, it may be necessary to fertilise the blossoms by using (very gently) a dry brush on the end of a stick, made of a hare's tail, soft feathers, or fur. This should be carefully dusted over the blooms, passing the brush from one tree to the other, so that no variety is fertilised with its own pollen. This little trouble ensures a regular "set" all over the trees, instead of clusters of fruit on some spurs and none on others; and as the fruit will ultimately be thinned to about one fruit on a spur, it is worth the attention.

As the growths begin to lengthen, watch must be kept for aphides or flies. It is not advisable to fumigate whilst the trees are in blossom, so that patches of aphis found here and there are best dusted with tobacco powder; but as .soon as the blossom petals have fallen, the house should be fumigated thoroughly, repeating the operation in two or three weeks' time. As soon as the fruits are easily discernible, the trees may be syringed over in the afternoon, closing the house at about 4 o'clock. The fruits will soon begin to grow; but do not attempt to 


\section{PLATE IV}

Apple: Cox's Pomona

(Ripens in October; suitable for the dessert or for cooking.)

Apple: Cox's Orange Pippin

(The best dessert Apple.) 


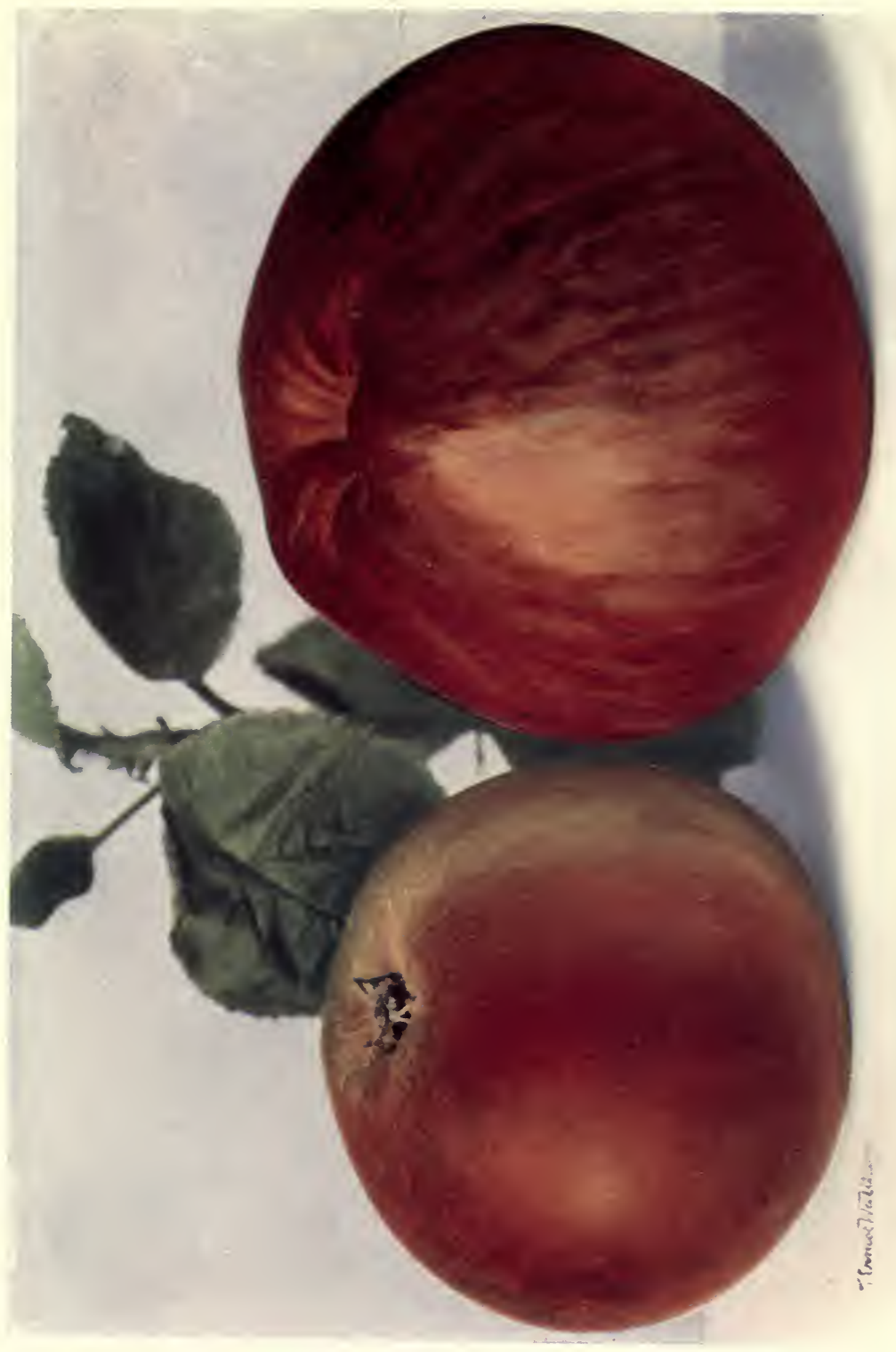




\section{THINNING AND MANURING}

thin them too soon. Many will fall off naturally, and the syringing will detach those which are not fertilised. About the middle of May it will be time to give the trees a slight thinning over with a pair of sharp grape scissors, reducing clusters of, say, 4 or 5 set fruits to 2, when, should more fall off, two may be left together; but it is not wise to leave too many, as the roots of the trees being confined in a pot, they cannot support such a crop as they would outside with a 6-foot root run. At the commencement of June the roots will have exhausted most of the nutriment in the soil, and the trees must be fed. This matter requires care, as the roots can only take up a certain quantity of food, and if the stimulant is too strong the roots will suffer; the tree will first have its leaves turn yellow and then they will fall, therefore all artificial manures must be well diluted.

It is safe to begin with some cow's dung placed in a porous bag in the water-tanks. This will gradually give out its properties to the water; but the liquid should not be allowed to get a darker colour than ale, and it may be applied to the roots about once a weak. One tank can be kept for clear water for syringing and watering, and the other for manure water. The next change should be limewater. This helps the formation of wood growth and also breaks up the insoluble stimulants in the soil, making them fit for absorption by the rootlets. In July the sun will cause rapid transpiration from the leaves, and it may be necessary to syringe the trees every day, besides giving water to the roots. In the same month a further help should be given them by forming a ring of cow-dung at the edges of the pot rim to form a sort of basin; where 


\section{PRESENT-DAY GARDENING}

malt combings can be had they are useful combined with the dung. This rim prevents waste of water, and at each application some stimulant reaches the roots; the upper fibres will soon root into the manure itself.

If there seems any check in leaf or fruit development, or the leaves lose colour, a teaspoonful of sulphate of ammonia can be given each tree, watering it in, and a bag of soot may be substituted for the cow's manure in the tank.

In order to get colour in the fruit, about the first week in August the pots may be shifted out-of-doors to a spot previously prepared for them on an ash bottom; but the trees must be carefully netted to protect the fruit from birds. We use a cage about 80 feet long and 9 feet wide, made with iron supports and covered in with half-inch meshed wire netting. It is remarkable how soon the fruits develop colour with the outdoor treatment, especially after rains and wind.

If the fruits are not wanted for any special purpose, the trees may remain in the house, as the flavour will be good even if the fruits lack that high colour to be seen at the exhibitions.

When a tree has been stripped of its fruit, it should be placed outside on an ash bottom and watered regularly; some loose, long manure may be placed between the pots to prevent drying out.

We will now suppose that the fruit is all gathered and the pot trees have been placed outside to "summer." The next step is to prepare soil for the annual repotting. This should consist of turfy loam which has been laid up a year previously, with a layer of short manure between 
every foot of loam. The turf should be cut down with a spade, chopped fine, and, if grassy, the clods with old grass should be laid on one side, to place grass-downwards over the crocks used in repotting. The compost should consist of loam 3 parts, and lime, old mortar rubbish, or burnt earth 2 parts. To each barrow-load of this mixture add a 6-inch potful of Clay's fertiliser, or similar stimulant, and an equal quantity of crushed bones; then mix all the ingredients thoroughly together.

This mixture should be placed in the orchard house, so that the potting can be done on wet days, and it is best to get this work over before Christmas. The Chrysanthemums should be all over in time to allow this to be done. The pruning of the trees should be done before they are repotted.

In the act of potting, the operator lifts the tree out of the old pot and removes the crocks from the base of the pot-ball, and also the top soil and the ring of manure. He then takes a hand-bill and, in the case of Apples and Pears, chops off one-third of the fibres which enclose the ball. These fibres being annual growths are not of great importance to the tree, and beyond the fibres there may be some coarse roots at the base of the ball which require reducing. This is readily done with a pair of "Secateurs," but no tree should be denuded of too many roots. In many cases the trees need not have a larger pot than before, but it is essential to have all the old pots washed inside and out to prevent stagnation of the soil.

Having prepared a clean pot, if needful a little larger than before, the potter places crocks all over the base 


\section{PRESENT-DAY GARDENING}

upon a larger piece of crock set over the hole in the bottom ; then he puts in the grassy lumps, grass-downwards, and throws in some loose soil, rams this down tight, throws a handful of loose soil on to it, and then introduces the tree, taking care to fill in round the sides of the ball with fine and coarse soil, which must be rammed in hard with a square stick, as it is most important that the soil should be made very firm. He then fills up the pot to within I inch of the rim, making the soil firm and leaving the surface finished level with fine soil.

During the winter the trees want but little water, but they should not be allowed to get quite dry, or the ball may shrink and allow water to run between the pot and the ball without really passing through the mass of earth.

In giving air, the lower ventilators opposite the direction of the wind should be opened in the earlier stages of growth, to prevent a direct draught.

If birds are troublesome, it may be needful to put a net round the lower ventilating shutters. This can be attached to the plate under the rafters from inside, so as not to interfere with the opening of the shutters.

Cherries can be grown in an orchard house to perfection, but they are best in a house by themselves, as they want more syringing than Pears and Apples, and are very apt to be affected by Black Aphis.

Apricots are not a success in pots as a rule, but in a cold house planted out they do admirably, and bear very freely. In this position it is possible to withhold water and thoroughly bake and dry them off, thus supplying the conditions of their native land (Syria). The side shoots 
should be spurred in in September, and the trees kept to a bush form by annual pruning.

Although this chapter deals with pot orchard trees in cold houses, there may be situations where a little artificial heat can be used to advantage : first, in the flowering season, when the temperature is apt to fall very suddenly and thus affect the set of fruit ; and later on, to finish the fruit in a cold, dull season, and to ripen the wood.

In many gardens this can be arranged by attaching a 3 -inch pipe to the existing hot-water apparatus. Such a pipe should flow all round the house if possible, but one flow will do if all-round pipes interfere with the entrance doors, which can be arranged to flow and return on one side only, bringing the flow out to the cinder path, so as not to cross any path. Such partial heating may also be useful to prevent damping in the Chrysanthemums in the later months of the year.

\section{CHAPTER VIII}

\section{FEEDING AND THINNING OUTDOOR TREES}

IN respect to feeding, two extremes are possible: first, over-manuring, either by the use of too much dung, or by the roots getting in to the quarters of richly manured vegetables; and, secondly, such poverty of soil as prevents the trees from fruiting in a satisfactory manner.

A golden rule is to withhold any stimulant from unfertile trees and to give it only to such as are bearing good crops. About June it can be seen what fruit has set, and 


\section{PRESENT-DAY GARDENING}

the needful thinning should be done, as by that time all imperfect, unfertilised fruits will have fallen. Where more than two fruits set on a spur, remove all but a pair, and let these be as far apart as possible to allow for swelling; all one-sided and ill-shapen fruits must be removed. Then begin to give to trees that are heavily laden some liquid manure water-either the drainings from stables or cow-sheds, or manure water obtained by placing a coarse bag of cow's or sheep's dung into a tub of water-but do not employ the liquid until it is properly diluted. Give the trees a good soaking, and the next day lightly hoe the surface around the trees. Then add a mulch of half-rotten dung, I foot from the stem, 2 feet wide, and if the weather proves dry, water on this once a week. If, however, the soil is rich already and the fruit does not swell gradually, an application of lime-water will be useful. Again, if there is lime in the soil, a few ounces of sulphate of ammonia or nitrate of soda just scratched in the surface soil will at once stimulate growth. But beyond this it is wise to give the trees potash and phosphatic manures in the form of wood-ashes, or by using basic slag or soot, whether they are bearing fruits or not. This should be sprinkled over the surface and be just scratched into the soil, so that the rains will carry the fertiliser direct to the upper roots. Nitrate of soda or Kainit should not be used on clayey or damp soils. The want of potash is most felt in old gardens' where the fruit-trees have been growing for many years and have thus exhausted the soil. Bone-dust and horn shavings are good manures, but they must be used sparingly. Canary guano as sold in tins by florists is also very suitable. Stimulants are required most of all by 


\section{CHOICE PEARS}

late Apples and Pears, which must be left upon the trees as long as possible, even into November, if the foliage is still hanging, for a little frost will not do them any harm.

\section{CHAPTER IX}

\section{CHOICE PEARS FOR OUTDOOR CULTURE}

HERE we have a large number to select from, but we shall proceed on the same lines as for Apples. The following six varieties are for small gardens. They are dependable bearers upon the Quince stock, as bushes or pyramids; and the fruits possess good flavour.

Conference, an attractive fruit of some length. (October.) Louise Bonne of Jersey, very juicy. Growth, slender. (October.)

Durondeau, a rich, russety fruit. Growth, free and upright. (November.)

Emile d'Heyst.-This variety seldom fails to crop well, and the fruits are of splendid quality. (November.)

Fondante Thirriot, a great bearer of compact, upright growth. (November.)

Doyenné du Comice, a moderate bearer, but the best dessert Pear in cultivation. (November to December.)

All these sorts ripen in October and November. Should earlier fruits be desired, in bush form, add Aspasie Aucourt for August, with Williams' Bon Chrétien for September; and where large, handsome fruits are desired, the following varieties may be selected :-

Souvenir du Congrés. (September.)

Beurré d'Amanlis. (October.) 


\section{PRESENT-DAY GARDENING}

Marguerite Marillat, very large and of rich flavour. (September.)

Le Brun, a green Pear of excellent flavour. (October.)

Pitmaston Duchess, very large. (October.)

Pretty, free-bearing, small Pears for children are Doyenné d'Eté (July), Petite Marguerite (August and September), Colmar d'Eté (September), and Belle Julie (October). These latter varieties are all great bearers.

\section{PEARS FOR CORDONS}

A favourite form of growing Pears is as cordons on fences or walls at 2 feet apart. All those before named are suitable, and the following varieties may be added :-

Clapp's Favourite (September), Fondante d'Automne (September), Beurré Hardy (October), Beurré Superfin (October), Beurré Alexandre Lucas (October), Glou Morceau (November), Beurré Diel (November), Nouvelle Fulvie (December to January), Easter Beurré (December), Josephine de Malines (January), Olivier de Serres (February).

All the Pears mentioned are good for espaliers in suitable soils, or for walls where proper conditions can be given them.

\section{PEARS FOR THE NORTH OF ENGLAND} AND SCOTLAND

The sixteen Pears first named in this chapter are all suitable, and those mentioned for cordons with the exception of Nouvelle Fulvie and Olivier de Serres. But in some districts choice Pears do not succeed except on warm walls, so that for the North the Hessle, Doyenné 


\section{GATHERING THE FRUIT 5 I}

Boussoch, Fertility, and Marie Louise d'Uccle are frequently planted. In unsuitable districts Pears should be grown as cordons in cold glass houses.

For the midland, southern, western, and eastern counties, and Ireland, all the Pears named are suitable, but they must be afforded deep, rich soils. Even in Kent there are districts in which Pears frequently fail to crop well. But, both as cordons and trained trees on walls, they may all be tried, as special soil can in that case be provided for them, and with attention to mulching, thinning, and watering, a good gardener will generally overcome difficulties of climate and soil.

It is best, however, to select such varieties as are known to succeed; and to plant them in various aspects to ensure the fruit ripening over a longer period than it would cover if the whole crop were grown in the same conditions. We prefer espalier Pears on the free or Pear stock, and such trees are best on chalky or sandy land.

\section{CHAPTER $\mathrm{X}$}

\section{GATHERING AND STORING THE FRUIT}

PEARS are very easily bruised, and the gathering basket should be lined with old blanket, or a soft material, so that the fruits will not be injured in taking them to the store. Large Apples should be treated with equal care. The basket should be carried by hand, and not be placed in a barrow to get shaken in transit. Handle the fruits carefully, and do not store any that are bird-pecked or such as show 


\section{PRESENT-DAY GARDENING}

signs of decay or black specks. All fruits should be gathered with their stalks, for if these are pulled out the fruits rot. To ascertain when Apples or Pears are fit to gather, cut one open; if the pips are brown, they are ready. With late Pears, gently raise the fruits, and unless they part readily from the spur, they should not be gathered.

\section{STORING THE FRUIT}

It must be remembered that the dry air of a room or closet absorbs moisture from the fruits and they become shrivelled and tough. It is a good plan to store small quantities in large flower or earthenware pots and cover them with a slate or tile, standing these in a cool cellar, and looking them over from time to time for removing decayed fruits.

This is mentioned because villa gardens do not often possess proper fruit rooms, but any sheds may be used for the purpose, as we seldom get sufficient frosts to freeze them before Christmas. Drawers are bad receptacles for storing fruits.

The smaller and harder Apples that do not ripen before November can be laid in heaps, covering them with newspaper or a cloth. But all early Apples are apt to sweat after gathering, and they should be laid out in a single layer until after the moisture has gone, when they may be laid up closer. Early dessert Apples soon lose their flavour, and that crisp texture so much appreciated, therefore it is best to use them direct from the tree. Many fine varieties have been condemned because they were eaten after their best period. 


\section{STORING THE FRUIT}

In early Pears the mistake is often made of leaving them upon the tree too long, when, after storing for a few days, they rot at the core or become mealy; whereas, if gathered a few at a time, taking the sunny side of the tree first, when they only part from the tree with some assistance, and before they commence to fall naturally, the season of use will be lengthened and the fruit will be rich and juicy. To find out when the later Pears become mellow and fit for use in the store, gently place the first finger and thumb at the end below the stalk, when if, on pressure, the flesh gives way, they should be fit for the dessert. If the crop is plentiful a fruit or two may be cut and eaten as a trial, and no more should be placed on the table than are wanted for the day's supply, as Pears after removal from a cool fruit room to the warmer air of a dwelling-house very soon get past their best.

In large gardens, a properly constructed fruit room or house is essential. It should be thatched on roof and sides, be match-boarded inside, and have double doors, with ventilation under the lower shelf from outside, and also in the apex of the roof to allow the sweat of apples to escape. These openings should have an outside shutter to be closed on frosty nights, or during high winds, and the floor should be of the natural earth, kept damp. In such houses, a supply of Apples can be kept eleven months in the year, and Pears until April.

The large reed from marshlands makes a durable thatch; failing this, heather or stout clean straw is suitable. Shutters must be provided for the windows, as the fruit keeps best when light is excluded.

A central stage is generally set apart to display the 


\section{PRESENT-DAY GARDENING}

finest fruits, and a series of side shelves on each side of the house, made of match-board, with $\frac{1}{2}$ inch space between each board, allows a circulation of air. The shelves should be $I \frac{1}{2}$ feet from each other, and a single layer of fruit should be laid on them. They will not require any covering.

\section{CHAPTER XI}

\section{PESTS OF THE APPLE}

IT is an axiom in gardening that "a healthy tree is generally free from disease." Therefore every care should be exercised to keep trees in that condition. Trouble arises from many causes, such as planting under the shade or drip of larger trees, placing the trees too closely together, planting too deeply, or planting in heavy soils that are not properly drained.

For all fungous diseases, including ordinary mildew, the best form of Bordeaux mixture is that sold as Voss' Woburn Paste, which is ready for use as a winter or summer spray. Leaf spot, and spotted and cracked fruits, will be less frequent after its timely use, say, in March before the leaves open, and again just as the fruit swellsthat is, unless it is necessary to spray for an attack of winter moth, when other mixtures are desirable in March or April. Sulphur mixtures such as Bunyard's Medela are also remedies for fungous troubles. In using wet sprays, care must be taken to cover both the upper and under sides of the foliage, and this should be carried out as a preventive where the trees have been attacked the previous year, before it again appears. 
A particular fungous disease on the foliage starts as a dull dark mass of brown spots, which soon spread, and working down the stalk of the leaf, affect the growing wood, forming pustules or pimples on it, developing later into canker. If disease is observed the new shoots should be cut hard back in winter to healthy wood buds, which may be found at the base of the shoots of the current year; the prunings should be burnt at once. Cox's Orange Pippin is very liable to this spot attack, which also affects the fruits and causes them to rot before they reach maturity.

Caterpillars.-Where Apples have been badly attacked by caterpillars, grease bands should be tied around the trees towards the end of October to prevent the female insects from ascending the stem, and the grease should be renewed at intervals until April ; otherwise it may get caked over, and thus allow the passage of the wingless females of the winter moth (Cheimatobia brumata). In February, the tops of the trees should be sprayed thoroughly with the caustic spray-fluid. This fluid is very powerful, and requires care to prevent it spoiling the user's clothes, getting in his eyes or on the skin, and a pair of india-rubber gloves are necessary to protect the hands. All similar sprays are dangerous if the operator has any, cuts on his hands. Trees sprayed with caustic soda may not be entirely freed from caterpillars, as there are other moths which lay their eggs in spring. For this reason a fluid spray of soft soap $2 \mathrm{oz}$. and quassia $2 \mathrm{oz}$. to a gallon of water, applied to the trees whilst hot, or M'Dougall's Wash, will benefit the trees just as the first leaves expand in April. In all cases follow strictly the directions given with any 


\section{PRESENT-DAY GARDENING}

particular specific. A weak wash may do no good, whilst an excessively strong dressing may injure the foliage and the flower-buds. These dressings will suffice until May or June, at which time, if any leaves are found adhering to one another, they should be pinched between the finger and thumb to kill the caterpillar enclosed in them.

Aphides.-A look out must then be kept for Aphis attacks. These flies or Aphides infest the young, tender shoots in July and August, and, if not checked, cripple the foliage and young growth. Tobacco-water made with $2 \mathrm{oz}$. of coarse shag to a gallon of warm water, or quassia and soft soap, are good remedies, which must be used again in ten days' time, as the eggs of a fresh brood may then have hatched out, and some of the older brood may have escaped, notwithstanding the care of the operator.

At the commencement of June the fruits will need attention. Any which are spotted with fungus should be collected and burnt, and, if need be, another weak dressing with the Bordeaux mixture should be applied if the spotting is spreading. It is much more prevalent in cold, wet seasons, such as 1909 and I9Io, than in a warm, dry summer. It must always be remembered that the spores of fungous diseases are carried in the air, and thus spread to other trees, so that it is most important to follow up the treatment and to burn all cuttings and affected fruits.

American Blight (Schizoneura lanigera). - We have dealt with fungous and Aphis troubles, but a very serious enemy to Apples is the American Blight or Woolly Aphis, which attacks Apple trees, settling in the rough bark, in cankered boughs, or in the axils of the leaves where they join the shoots. 


\section{PLATE V}

Pear : Durondeau

(Suitable for private or market garden culture. Ripens in November and December.) 



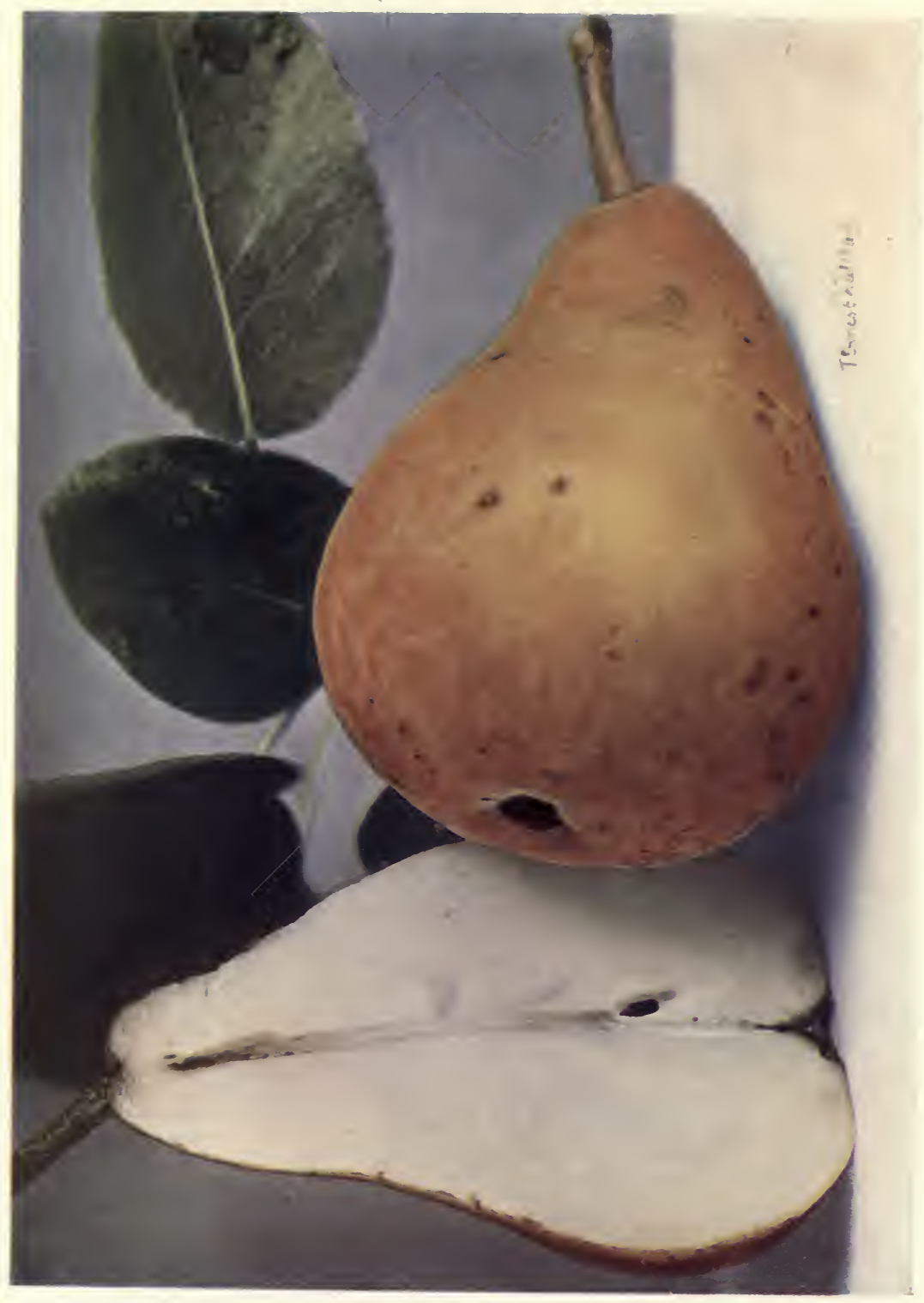


It appears as a white, cottony mass, the insects in this way protecting themselves, so that a wash passes over them, and they can only be killed by rubbing in methylated spirits of wine, in isolated cases, or by the use of Gishurst Compound, applied with a rather hard brush, repeating the application after ten days to kill the new brood. Not long ago a painter's blow lamp was recommended as effectual, such as is used to burn off paint; but such a remedy must be used with great care or there will be some danger of burning the growing wood. As the Woolly Aphis hibernates in the soil near the tree and in the uppermost roots, they should also be searched for there in late autumn. In severe cases an injection of bisulphide of carbon with a special machine made for the purpose has been found effectual. After the cankered places have been cleared of this blight, cut the rough bark away and smooth the portion over, so that new wood may cover up the affected parts.

Weevils.-These are difficult to destroy, as they feed by night. The insects are of a dull, earth-brown colour, which hide by day in the soil. They may be caught by tapping the trees at night and shaking them on a cloth, or by levelling a portion of the soil and placing on this a flat stone, which, if lifted in the day, will reveal the Weevils secreted beneath it. On first lifting they do not appear, but after an interval they may be seen to move their legs, and can then be picked up. They are most tenacious of life, but they can be killed by scalding water. They require louking for, as they are the same colour as the earth. There is also an iridescent day weevil, which can be shaken down on sight. It is quite a small bug-the size of a ladybird. 


\section{PRESENT-DAY GARDENING}

The Ladybird (Coccinella) is well known as a friend, but its black larvæ is also a foe to aphides, and should by no means be killed, as we fear it often is.

Red Spider.-The foliage of Apples, especially those of a hirsute character, are liable to be attacked by red spider, which causes them to assume a rusty look. The insects are very minute, and form a slight web over themselves. A severe syringing with tobacco-water and soft soap will check them, and after applying this, syringe again with tepid water in two days' time. This will generally clear the trees, but it is necessary to syringe well under the foliage to make sure of dislodging the pest.

Canker.-Amongst the contributing causes of canker may be mentioned undrained soil, or soil which lacks some essential element, also bruises upon the bark, or injuries caused by small shot in scaring birds. In bad cases on the older boughs it must be combated with drastic measures. With a sharp knife and chisel cut away all the rough, scaly bark and any dead, brown wood that is found. Carefully smooth over the edges and apply painters' knotting or a Blight Cure to the wound. This will keep out the wet and allow the new bark to grow over and heal the wound. Treat the smaller boughs in a similar manner, but not so severely. If canker is present at the ends of the boughs, cut them back to healthy wood to induce new growth. In some cases, root-pruning will help the trees; and in others considerable benefit will follow the application of artificial manures such as sulphate of iron, basic slag, and sulphate of ammonia, using $2 \mathrm{oz}$. to the square yard; but these remedies are useless if the lower roots are in a clayey or wet soil. Some Apples, such as 
Lord Suffield, Ribston Pippin, Peasgood's Nonsuch, and Dumelow's Seedling, are extremely liable to canker, the direct cause of which is the fungus known as Nectria ditissima.

The Mussel Scale is a small, silvery-looking insect which lives under a shell-like covering. It is often prevalent on Apples, especially in dry soils, or on Apples and Pears grown on walls. An application of Blight Cure will check them, and if this does not complete the remedy, they may be stifled by an application of sweet oil, which closes their breathing apparatus. After this has been done, scrub the trees with soft soap or Gishurst Compound, and the bark will then become healthy and allow the boughs to swell.

Apple Sucker.-The female of the Apple Sucker lays its eggs in the buds of Apples just before they open into bloom, and it can be found where these buds adhere together as a big-headed green bug, almost transparent. It soon grows and eats the productive organs of the flowers, so that although the blossoms may appear to be perfect, they lack the female organs and are incapable of developing into fruit. The only way to check this pest is to spray the trees at this period of the unfolding of the flower-buds with M'Dougall's Wash.

Mildew.-A superficial mildew on the shoots should be treated with sulphur, but as mildew is most common in autumn, such affected shoots can often be cut off and burnt.

Unfertility.-Unfertility in Apples may be caused by the trees, in a young state, making too much wood, whether brought about by overfeeding or by such hard pruning as is conducive to excessive growth. The remedy for this is 


\section{PRESENT-DAY GARDENING}

root-pruning, an operation I have described on a previous page. If a tree blossoms well the cause of unfertility must be looked for in some other direction, and no good will result from pruning the roots.

The untrained jobbing gardener is often the cause of failure in fruit crops, as his idea of pruning is to cut and hack the tree all over, including the fruit spurs. Again, sparrows are sometimes to blame, for in gardens near to towns they eat the fruit buds, and even in the country the bullfinches will clear the buds from whole orchards of trees.

\section{CHAPTER XII \\ PESTS AFFECTING PEARS}

PEAR pests are, in some instances, similar to those of Apples, such, for example, as canker, leaf spot, aphides, and caterpillars, but Pears are not attacked by the American Blight. The remedies for the above pests can be used as advised for Apples.

Pears have one serious insect pest in the Pear Midge (Diplosis pyrivora). The female midge lays its eggs in the opening flower-buds, and the larvæ upon hatching at once enter the ovary to feed. The Pears appear set for fruit, but, instead of making a pyriform growth, they become globular, and drop to the ground; the larvæ then leave the fruits and bury themselves two inches or so in the soil. If an affected fruit is cut transversely the minute, white larvæ will be found in possession. Affected fruits must be at once collected for burning, and the surface soil around the trees should be dressed in the winter with 


\section{CALENDAR OF OPERATIONS $6_{3}$}

Kainit, using $4 \mathrm{oz}$. to the square yard. If Kainit is applied before February it may prevent many of the larvæ in the soil from coming to perfect insects.

Pear Slugworm.-Another summer insect which attacks Pear leaves is known as the Pear Tree Slugworm. It is the larva of the Cherry and Pear Tree Sawfly (Selandria atra). The Slugworms are small, jelly-like insects, in shape like a clove. They eat the green part of the leaf, which turns brown and curls up. Occasional dustings with lime or Hellebore powder will soon clear them off.

There is also a very minute mite which makes yellow dots and blisters on the foliage. For this pest a spray of Medela is advised, two applications at intervals, in February and March, before the leaves appear.

\section{CHAPTER XIII}

\section{CALENDAR OF OPERATIONS IN HOME} FRUIT GARDENS

\section{JANUARY AND FEBRUARY}

Complete the pruning of Apple and Pear trees. As sparrows may be troublesome, do not prune Gooseberry and Currant bushes until March.

\section{MARCH AND APRIL}

See that all espalier, cordon, and standard trees are firmly secured to stakes. Early in April a few trees will be unfolding their leaves and flowers, and a watch must be kept to destroy caterpillars. They can be picked off if only 


\section{PRESENT-DAY GARDENING}

a slight attack, but if general, spray the trees as directed. Grafting can be done during these months.

\section{MAY AND JUNE}

Keep a watch for aphides and caterpillars and destroy them. Thin out the fruits on Apple and Pear trees that are heavily cropped.

\section{JULY}

Train the shoots of Apple and Pear trees where they are required for extension of the branches, but do not do any pruning during this month. Continue thinning out the fruits upon trees that are carrying heavy crops.

\section{AUGUST}

The inner shoots of pyramidal and bush trees that are not required permanently may now be shortened to four leaves, and espalier, cordon, and wall trees should be summer-pruned. Budding should be commenced this month. Fruit-trees may be watered if the ground is dry.

\section{SEPTEMBER}

The fruits will now be rapidly swelling, and showing colour. After the needful pruning has been done, a few leaves may be removed round the fruit to admit the rays of the sun. Red Spider on Apple trees should be checked according to the directions given in a former chapter.

\section{OCTOBER}

If any new growths have formed where the summer pruning has been done, the shoots may be rubbed off with 


\section{CALENDAR OF OPERATIONS 65}

advantage. See that all leading shoots are secured where needed for extension. In this month notes should be made of new varieties to be ordered for filling blanks, or to lengthen the fruit supply by obtaining earlier or later ripening varieties. All useless trees should be marked for destruction. Open ground for fruit-trees should be dug up roughly at the end of October to expose the soil to the influences of frost and air.

\section{NOVEMBER AND DECEMBER}

These are the chief planting months. If fruit-trees arrive at a time when they cannot be planted, open the bundles at once and lay the trees in the soil, covering the roots ; they may then be planted when it is convenient. If on unpacking the trees the wood is shrivelled and the roots are dry, immerse them in water for twenty-four hours. It is rare for frost to injure trees in transit, but this may occur when the weather is favourable at the place of despatch but suddenly changes before the trees reach the purchaser. On receipt they should be laid in a frost-proof shed and be kept dry, and no harm will ensue. The author once had ten thousand young trees in a shed when the temperature fell to zero ; they were kept dry, and not one failed. If caterpillars have been troublesome on the foliage during the past season, some grease bands should be put round the stems of the trees before November $5^{\text {th }}$; if this treatment is followed in January by a dressing of lime and salt applied in January, well washing it into the bark, many insects will be killed. 


\section{PART II}

\section{CHAPTER XIV}

\section{CULTIVATION OF APPLES AND PEARS FOR PROFIT}

WE now enter upon a fresh subject, and the most important question is, What sorts can be grown to give a reasonable profit on the outlay?

In former chapters we have described the manner of planting, style of pruning, and hints have been given on the purchase of Apples and Pears. But, good as all the sorts recommended for garden planting are, we now come to the business part of the industry, and have to take other matters than the supply of a family into consideration. In the commercial cultivation of fruit, the following maxims must be borne in mind :-

r. Do not plant too many varieties.

2. Do not plant blocks of a kind together.

3. Plant on arable land if this is possible.

4. Do not put all your eggs in one basket, but start with a mixed plantation.

5. Do not go all over the country seeking advice; go to one authority and act on his recommendation. 


\section{MIXED MARKET PLANTATIONS 67}

6. Do not bother about markets until you get a crop.

7. Get land near a railway station or big town if you can.

8. Do not acquire land merely because it is cheap, nor purchase without expert advice.

9. Do not prune the trees the first year after planting.

Io. Be sure to wire the hedges and keep out rabbits.

II. Provide shelter from prevailing winds.

12. Do not buy trees at auctions, but, instead, visit the nurseries in August or September, if you contemplate planting.

\section{Keep fowls and pigs.}

Too many Varieties. - The market salesmen make much better prices when the supply of any one variety is continuous. Small lots, unless they are of exceptional quality, make low prices. Therefore, plant boldly from one to three hundred trees of one variety of Apple or Pear, and also of Currant or Gooseberry. At the same time a special plot of trial varieties may be planted to find out the best sorts for the district, in view of further extensions.

Not Blocks of one Kind.-Experience has shown that where a number of trees of one variety of fruit is planted, the flowers do not set so well as when pollen of several varieties is available for their pollination. Not more than three rows of the same variety should be planted together; the next three must be of another variety, when the first three can be again repeated. It has been found that in large blocks only the outside trees have been fruitful, being fertilised by bees or wind-carried pollen, whilst the trees in the centres of these blocks have been barren. Bees should 


\section{PRESENT-DAY GARDENING}

be kept in all plantations for the purpose of getting crossfertilisation of the blossoms.

It is best to start a mixed plantation in arable or cultivated land-that is, standard trees with rows of bush trees between them, the latter being again interplanted, or " middled" as we say in Kent, with red or black Currants, Gooseberries, Raspberries, or Strawberries, for some ten years, by which time the "under fruit" or bushes can be removed. The planting of standards in grass entails expense in providing protection from cattle; but where it is intended to lay down the orchard eventually to grass (say in ten years), it is not advisable to plant bush treesmeanwhile the open land may be cropped with Potatoes or Mangolds, but not corn.

The largest returns are obtained from mixed plantations, and it is seldom that such fail to yield a profit. Should the Apples and Pears not be fruiting that season, the other fruits may succeed, and the needful culture of bushes is a great help to the development of the Pears, Apples, or Plums planted amongst them.

A mixed plantation is the most expensive at the outset, but it soon yields a good return. Strawberries yield a crop the first year and Currants the second, whilst Apples and Pears, if dwarfs, begin to crop in the third year, or, as standards, in the fifth season.

Too many Inquiries. - We are so often consulted by intending planters who have interviewed gardeners, salesmen, and growers, and whose ideas are therefore so mixed that they do not know where to begin, that we strongly advise all to consult one expert and then go ahead. These inquirers often bother their heads about markets, baskets, 


\section{LAND NEAR TOWN OR RAIL 69}

and salesmen's charges before they have any prospect of a crop. This wasted energy should be put into the planting and cultivation of the land, and it will amply pay for the attention.

Land near to a Town or Railway.-Planters on a large scale will do well to give this matter full consideration. Proximity to a railway provides facilities for prompt despatch of produce, and also convenient carriage of manure from the cities or towns. But land which is situated near to a town or railway station is so much dearer that it may pay better, after all, to get land which is further afield, as a horse and van are needed for road cartage and also for work on the land, and once fruit is loaded up, a few extra miles are not very serious. Much time can be saved by arranging purchases to be brought back in the van.

Cheap Land.-Many planters have had cause to regret that they commenced cultivation on a particular piece of land merely because it was cheap. If the soil is clay it requires first of all to be artificially drained, and afterwards it needs years of tillage, before it is brought into a good working condition, and, if situated in a valley, serious losses are likely to be suffered from spring frosts. Hungry, sandy soil requires very much manure to make it fertile, and the virtue of applied dung so soon gets washed below the feeding roots, that this soil also proves very expensive. Good loamy soil is easier to work and more lasting. Thin, chalky soil is often too dry in summer and should be avoided.

Purchase of Land.-It is best for planters to buy freehold land, if their capital will permit them to do this, or even to purchase land, and let half the money be raised 


\section{PRESENT-DAY GARDENING}

on a mortgage. But before completing a purchase, the beginner should get some expert advice from a friend, or, failing that, pay a fee to a competent man, and have the soil tested in several places. In any case, do not be rushed into buying by such remarks as "Well, give me your reply soon, as there are others after the site."

Defer Pruning.-Don't prune the first year, except such Plums, Damsons, Gooseberries, and Currants as are planted before Christmas. We are very strong on this point, because unpruned Apples and Pears recover themselves so much more quickly, making much earlier leafage than trees which have been pruned. Remember always that it is wise to form a tree before you allow it to fruit. Trees pruned on planting form little growth, but plenty of fruit spurs, and these prevent a good sound foundation being laid for a vigorous tree.

Wiring the Hedges.-If hedges already exist, cut the inside face in close and upright, and then sink the wire netting 9 inches below the ground level, turning the lower edge outwards if possible. Attach the upper part of the wires to the hedges as close as possible. The hedge will then grow through the meshes and help to keep it in place. It is absolutely needful to wire all plantations to keep out rabbits, using $\mathrm{I}$-inch mesh wire, $3 \frac{1}{2}$ feet wide for this purpose. Where standard trees only are planted, each tree should be wired separately. In wiring standard orchard trees, which are best secured by two stakes, the wires must be attached to the stakes, not to the tree. Otherwise, in summer sheep or young cattle will rub against them, and the wire will cut into the tree bark. The position where the tree is secured below the head will 
require attention annually, to destroy insects which harbour in the straw tied in for protecting the bark. This must be burnt, and the new ties should be placed above or below the previous ones.

Shelter.-If the new plantation is in open fields, it will be best to plant a belt I 8 feet wide with Scots or Austrian Pines, putting these at I2 feet apart, and fill in with Larch at 3 feet, placing an Ash between each Pine, to be cut down after five years' growth to form a stool to produce wood for stakes. There should be three rows in the length ways, and the plants should be arranged to angle. If this space cannot be spared, a single line of Italian Poplars at 8 feet apart will answer. Poplars grow quickly, and can be cut yearly to flatten them. Other shelter trees are rows of Damsons or Kentish Bush Plums, at ro feet apart, or the Crawford or Capiaumont Pears.

According to the slope of the ground or the prevailing winds, shelter may only be wanted on one side, the others being hedged with Quick (Thorn), planted at nine to the yard. It is best to let Quick grow one year, then cut it down to I foot, and the following July just cut the tops off and trim the sides up, always bearing in mind that the hedge should be formed like the letter A. Cut it in rather closely for the first few years to get a good base, and afterwards let the hedge grow 6 feet high.

Purchase of Trees. - Those who contemplate planting should visit the nurseries in September and see the trees growing and the experimental plots. This experience will give them a practical insight into many things that may have escaped their notice in books. 


\section{PRESENT-DAY GARDENING}

Value of Fowls.-Keep fowls on the fruit lands, and let them run over the ground, especially when the land is being dug and after the crops are gathered. Their manure is very valuable mixed with earth and stored dry. Also, if possible, keep pigs in order that they may eat up all vegetable rubbish grown. Mix in the ashes from the house with the pig manure. Another plan, if no live stock is kept, is to dig a pit 4 feet deep and 6 feet square, and in this put all the kitchen and house refuse, ashes, and vegetable trimmings. They will rot and the manure will be useful on the land. For obvious reasons this pit should be made as far from the house as possible.

In reference to the commercial growth of fruit, the author is permitted to refer inquirers who wish for fuller information, to his sixth edition of Fruit Farming for Profit. It may be purchased, 2s. 9d. post free, from the Gardeners' Chronicle, Covent Garden, London.

\section{CHAPTER XV}

\section{PREPARATION OF THE LAND AND PLANTING}

AFTER a corn crop has been taken, the field should be broad-shared first, then harrowed, collecting the stubble and weeds for burning. Following this the field should be steam-ploughed (if of sufficient acreage) as deeply as possible in September or October, and the soil allowed 


\section{PLATE VI}

\section{APPle : Lord Derby}

(An excellent culinary Apple for use in November and December.) 



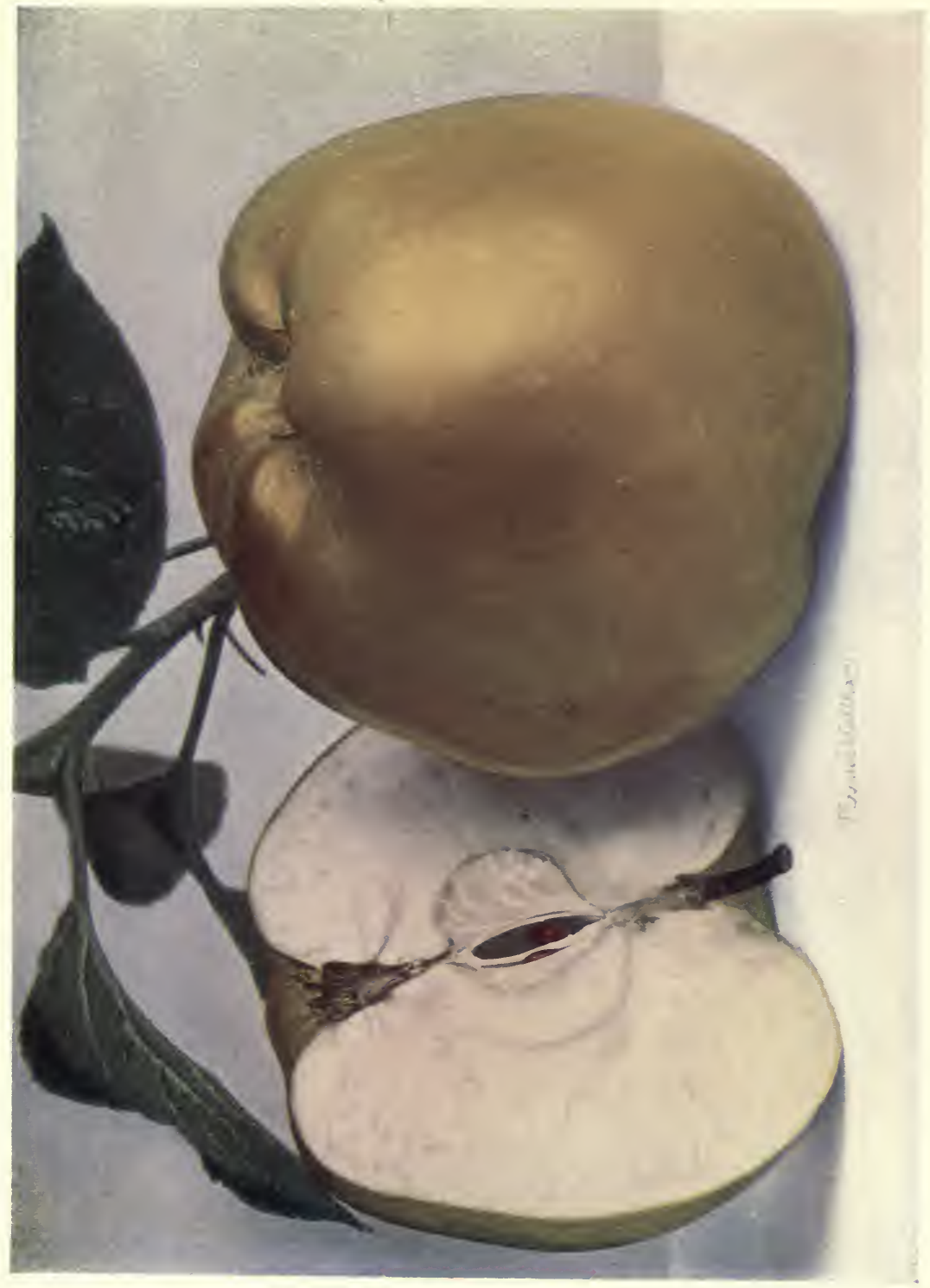




\section{APPLES FOR THE MARKETS 75}

to settle. Before planting in mid-November or December, let the harrow be run over it both ways to get a good surface tillage. If a small field it may be ploughed deeply, and then be treated with a subsoil ploughshare to break up the "pan" below the ordinary open ploughed furrow. If the furrows are exposed to a few frosts before the land is harrowed, so much the better. If the soil is infested with thistles, Couch Grass, Bearbind, or deeply rooting weeds, it will be best to defer planting for a season, and crop the land with Wheat, Oats, or Potatoes to get it thoroughly free from weeds, otherwise they will be very troublesome after the trees and bushes are planted. If Potatoes have been the previous crop, they will leave the land in condition for planting.

Planting.-All the rows should be quite straight and, if possible, so far apart that horse or pony hoes can be used to destroy weeds and to obtain a fine surface tilth, which hinders summer evaporation and allows rain-water to penetrate.

\section{CHAPTER XVI}

\section{APPLES FOR THE MARKETS}

THE following varieties may be cultivated either as bushes on the Paradise stock at 12 feet apart, or as standards or half-standards on the Crab stock at 18 to 20 feet apart. 


\section{PRESENT-DAY GARDENING}

\section{EARLY VARIETIES TO SELL AS GATHERED}

\begin{tabular}{l|l}
\multicolumn{1}{c|}{ Dessert Apples } & \multicolumn{1}{c}{ Cooking Apples } \\
Mr. Gladstone. & Early Victoria. \\
Beauty of Bath. & White Transparent. \\
Lady Sudeley. & Lord Grosvenor. \\
Worcester Pearmain. & Grenadier. \\
Ben's Red. & Stirling Castle (Dwarfs only). \\
Yellow Ingestre. &
\end{tabular}

\section{LATER VARIETIES}

\begin{tabular}{l|l}
\multicolumn{1}{c|}{ Dessert Apples } & \multicolumn{1}{|c}{ Cooking Apples } \\
James Grieve. & Golden Spire. \\
Allington Pippin. & Warner's King. \\
* Cox's Orange Pippin. & Lord Derby. \\
King of the Pippins. & Norfolk Beauty. \\
Duchess Favorite. & Royal Jubilee. \\
The above sorts require stor- & These can be sold from the \\
ing. & trees, or be stored to sell \\
& from October to Christ- \\
mas.
\end{tabular}

- Cox's Orange Pippin is not a success on some soils, but it has been found that it makes a capital stock on which to graft Bramley's Seedling, which then bears more regularly. This hint may be useful to those who have been unlucky with Cox's Orange Pippin, and prevent them destroying the trees. 


\section{CHOICE PEARS FOR BUSHES 77}

\section{LATE APPLES FOR STORING}

\section{Dessert Varieties}

Baumann's Red Reinette.

Barnack Beauty.

Christmas Pearmain.

Hormead Pearmain.
Cooking Varieties

Bismarck.

Alfriston.

Bramley's Seedling.

Newton Wonder.

Lane's Prince Albert.

\section{CHAPTER XVII}

\section{CHOICE PEARS FOR BUSHES}

THE following varieties of Pears may be grown as bushes on the Quince stock at 12 feet apart :-

Williams' Bon Chrétien (September), * Dr. Jules Guyot (September), * Petite Marguerite (September), Louise Bonne of Jersey (October), Beurré Van Geert (October), Conference (October), Durondeau (October), Doyenné Boussoch (October), Pitmaston Duchess (October), *Emile d'Heyst (November), Doyenné du Comice (November), Fondante Thirriot (November).

In planting, care must be taken to place the junction of the Quince with the Pear 3 inches below the soil, and the stronger growers should be alternated with

- These are very compact growers, and can be planted 6 feet apart. 


\section{PRESENT-DAY GARDENING}

the weaker. Do not plant more than three rows of one sort together, as this would hinder or prevent crosspollination.

All the Pears mentioned above are equally suitable for training against the walls of buildings or garden walls, also as espaliers or cordons.

Choice Pears must be gathered very carefully, as we have said in a previous chapter. Tomtits are often troublesome with Pears, as they settle on the stalk and peck at the end of the fruits, which will not then keep in store. Such imperfect Pears can be stewed. A few Sunflowers planted near will often prevent their depredations, as the birds are very fond of the Sunflower seeds.

\section{CHAPTER XVIII}

\section{PEARS AS STANDARDS}

There are some common Pears, such as the costers sell, which pay well for cultivation-although their quality is but second-rate-as they bear profusely and travel well; they mostly ripen early, and the trees have time to recover themselves the same season.

The earliest is the Lammas, a mealy fruit with a red cheek. This is followed by the Crawford or Chalky Pear of Kent, pale green with white, sweet flesh ; it is generally ready for the August Bank Holiday. Both these Pears 


\section{PEARS AS STANDARDS}

are often gathered ten days before this period and laid in heaps to ripen them for that festival.

The Hessle ripens in September. The tree is a great bearer, and the fruits are dull green with silvery specks. This is followed by Williams' Bon Chrétien, and in October Beurré Bosc pays well in good Pear land, also Beurré Capiaumont, a small Pear often brightly coloured. Rivers' Fertility is an improved form of Capiaumont, and Petite Marguerite is a sweet, round Pear which ripens in October, when Red Robin is also in season.

Owing to the habit of these Pears to crop very heavily, they are often undersized. The size may be improved by affording the trees a liberal surface mulch, in May, of fresh stable dung, or an application of manure water, or a dressing of nitrate of soda or other fertiliser. It is advisable to give this attention, because it assists the trees to bear the following season; otherwise they may require a year's rest to recover.

In winter it also pays to thin out the boughs, as even a rise of $6 \mathrm{~d}$. to Is. per bushel for improved quality will repay this attention.

Standards may be planted on arable or grass land.

It is useless to plant choice Pears unless the soil is suitable-such, for instance, as a rich, deep-brick earthbut the small sorts recommended above for standards are not so particular as to soil.

Perry Pears are not grown in Kent, but they may be purchased from some of the Midland nurserymen. 


\section{CHAPTER XIX}

NUMBER OF TREES PER ACRE

THE following table will give the proper distances trees

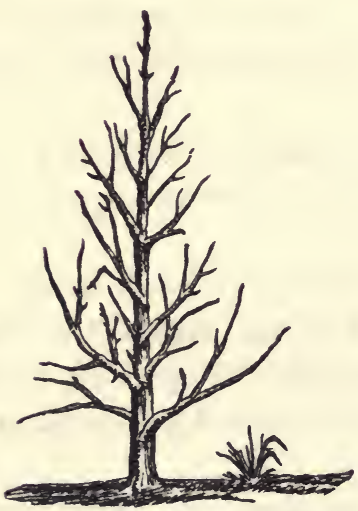

Fig. 3.-A Young Pyramid

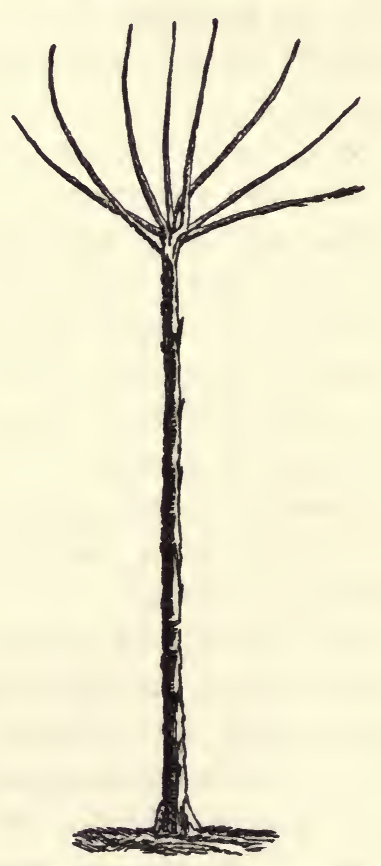

Fig. 4.-A Standard Apple Trek

and bushes should be planted apart, and the number required per acre. We give the details relating to Currants 
and Gooseberries, as these fruits enter into the question of the profitable cultivation of Apples and Pears.

\section{BUSH FRUITS}

Gooseberries, Red and Black Currants, at 6 feet apart, 2 10 plants per acre.

Black Currants are better at 8 feet, 680 plants per acre.

Bush Apples and Pears, at 12 feet apart, 300 plants per 2 cre.

These notes are given in case the planter should prefer the mixed plantation form, when the standard or permanent trees should be deducted from the above figures.

\section{STANDARD OR HALF-STANDARDS IN ORCHARD OR PLANTATION}

Apples of the smaller growing varieties, and Pears of close growth at 18 feet, 134 to the acre.

Apples and Pears of spreading growth at 24 feet, 74 to the acre. Apples in grass where pastured and it is not advisable to shade the pasture too much, at 30 feet, 48 to the acre.

It is good practice, where standard trees are planted at 24 or 30 feet apart, to place standard Plums midway between each row; when at 24 feet about 225 plums would be needed, or at 30 feet 140 plums would suffice.

A standard tree has a stem about 6 feet, and a halfstandard about $4 \frac{1}{2}$ feet. 


\section{PRESENT-DAY GARDENING}

\section{CHAPTER XX}

\section{PROBABLE MARKET PRICES}

THE prices which fruit will realise in the open market depend to a very large extent on the character of the season and extent of the crops. Speaking generally, the higher prices obtained in a scarce year are as satisfactory as the lower prices realised for full crops, because the cost of picking, packing, and marketing is higher in a bountiful year. An average price per sieve or bushel for Kitchen Apples would be about 3s. $6 \mathrm{~d}$. net to the grower, and for Dessert Apples sent in half-sieves about 3s. net. For choice boxed specimens of early Apples, about is. 6d. a dozen may be expected; for Cox's Orange Pippin and similar varieties, from 2s. $6 \mathrm{~d}$. to $4 \mathrm{~s}$. a dozen; other later dessert kinds, about $3 \mathrm{~s}$.

These are wholesale prices, and if small growers can meet with private customers in the locality they may make double the above prices. Some growers supply hotels, especially at seaside resorts, at high prices. In dealing with small shopkeepers there is always a risk of incurring bad debts, and it is advisable to insist upon having cash on delivery.

Pears of the commoner sorts are best sold in sieves, and they make prices varying from Is. to $4 \mathrm{~S}$. per sieve; better-class fruits, in half-sieves, from 2s. $6 \mathrm{~d}$. to $4 \mathrm{~s}$. All 


\section{PACKING FRUIT FOR SALE 83}

large and choice Pears should be packed in boxes, when $2 \mathrm{~s}$. to $4 \mathrm{~s}$. per dozen may be realised for them. Large fruits of Doyenné du Comice with clear skins, from walls, make up to Is. each.

\section{CHAPTER XXI}

\section{PACKING FRUIT FOR SALE}

THE matter of grading should have careful attention from growers, as it is of vital importance. All kinds of Pears and Apples pay well for grading, and when marketed as firsts, seconds, and thirds, will usually realise 50 per cent. more than the same fruits would sell for if sent to the market unsorted.

Large growers should register a special "brand" name on a distinctly coloured paper, and thus secure a reputation for quality and honest packing. The printing of the paper, after the first cost of a wood block, would be but a small charge, and a half-sheet could be placed after the usual packing paper had been bent over the top of the basket, the corners being turned down into the basket rim.

When once a reputation has been thus built up for high quality, it not infrequently happens that the produce is all booked before it reaches the markets, at prices greatly exceeding the rates of the day.

The packing and grading of Apples is a matter of the most serious import for the future of the British fruit trade. Success depends largely upon the growers adapting themselves to modern methods of marketing. They must realise that 


\section{PRESENT-DAY GARDENING}

the growing of the fruit is but one part of the business, and the more difficult question of selling it to the best advantage must be met and overcome. In regard to cultivation, it must be remembered that a bushel of bad fruit costs more to pick, and as much to market, as an equal quantity of first-class fruits. Packing in branded boxes will enable a reputation to be built up and secure a new opening for sale, namely, that of the wholesale grocers, who will be only too glad to buy English fruit if it is packed in a manner that they can handle it. The packing must be attractive and the fruit uniform in quality and size; the grower who fulfils these conditions should, in a few years, be able to deal direct with the wholesale grocers, thus saving the intermediate profits which now press so hardly upon him.

Choice Dessert Apples may be placed 12 in a box, nested in wood wool so that they do not touch each other. Smaller sizes may be arranged 18 to 24 in a box, and choice Pears in the same manner. Several boxes can be tied together to travel as one parcel. After the fruits are placed in the boxes, cover them with thin, soft paper, and over this place some wood wool so that the fruits will be kept firm. The best white wood wool only should be used.

The author was much interested recently in an institution called the Hereford Co-operative Fruit Grading Company, Limited. This concern has been in operation for two years, and is increasing in favour with growers. All fruit is sold by weight, and is well packed and branded Ar, or quality I-2-3. This work is done by women, and the cost appears to be about $3 \mathrm{~s}$. per cwt. to the growers, who are subscribers of $5 \mathrm{~s}$. a year, and are bound to send in all 


\section{PACKING IN "HALVES" 85}

the fruit they produce. This fruit is all packed in nonreturnable boxes.

One private grower, who makes a speciality of choice Apples (Cox's Orange Pippin) finds a ready sale for them in boxes holding 18,24 , and 36 fruits, which he sells at the same price. They average about $5 \mathrm{lbs}$. in weight, the boxes of 18 being the finest, selected fruits. This culture can even be undertaken by private people, ladies or gentlemen, as a paying hobby, and no doubt larger growers will also take up such a profitable system of sale, as in that way they can realise double or treble the market value of bushel packages.

It is now the custom to pack nearly all hard fruit for Covent Garden, or other London markets, in baskets called "halves" (half-sieves), which hold, nominally, four gallons. I should like to say just a word against the practice of putting large cooking Apples in half-sieves. This is by no means a good plan. A "half" of large Apples does not contain more than three or four layers, and in packing, loading, and in the general knocking about the basket gets before reaching its final destination, the bottom layer becomes bruised, whilst the top layer suffers in the same way from the pressure of packing sticks. The result is that there is only one or, at most, two layers that open in good order. If the same fruit were packed in bushel or hundredweight barrels, the bruising would be necessarily much less, and the fruit sell better. Dessert Apples are best placed in half-sieves, but for other kinds the larger package is much the best.

Customs die hard and buyers still prefer the basketpacked fruit. A "half" of fruit weighs about $24 \mathrm{lbs}$., and 


\section{PRESENT-DAY GARDENING}

a sieve 48 lbs. It is, however, to be hoped that all fruit will ultimately be sold by weight. This was approved by the 1907 Fruit Conference, but the smaller buyers cling to the old custom.

\section{CHAPTER XXII \\ WAYS AND MEANS}

BEGINNERS may want to know the probable cost of laying out a plantation of Apples or Pears. In this case much depends on the price of local labour, the condition of the land, and whether the proprietor works at the job himself. Moreover, it will be obvious that it is cheaper, pro rata, to lay out ten acres than one.

It is, however, essential that the planter should have sufficient capital to last him for the first three years of planting, for although the catch crops may bring in a little ready money, a plantation of Apples or Pears will not begin to pay until the fourth year if the trees are dwarfs, and the fifth or sixth year if standards are planted. But if a mixed plantation is decided on an earlier return is secured.

In an orchard composed of standard trees at 48 to the acre, the cost of trees, planting, and securing the stems with netting would be about $£_{\mathrm{r}}$, and for half-standards about the same, for, although the smaller trees are cheaper, they are generally planted closer together.

In a plantation of dwarf bush trees no stakes are needed, 
and with 300 trees to the acre the prime cost would be about $£ 30$ to $£ 35$ for trees of two years old, and say f5 extra for older trees. If middled with Gooseberries and Currants the cost would be about $f_{\text {Io }}$ per acre more.

After the mixed plantation is made, labour generally, including picking, would be about $£$ ro per acre annually. That is to say, that if five acres were laid down, a planter should start with a capital of $£_{2} 200$, and beyond this have enough to keep him for three years. Some might do with less, as one man may succeed where another fails.

The cost of standard Apples and Pears ranges about f7 per roo for well-grown, clean trees, and for halfstandards, $£ 4$ to $£ 5$, and for two-yeàr trees, as dwarfs on Quince or Paradise stocks, from $£ 4$ to $£ 5$ per 100. Bush fruits, from Ios. to 20s. per I00. Raspberries for planting, from $\oint_{\mathrm{I}}$ per I000, and Strawberries from $7 \mathrm{~s}$. to I5s. per I000, according to the time of year.

The best plan is for buyers to state their requirements to a reliable firm of nurserymen, and get a special quotation for free delivery.

\section{CHAPTER XXIII}

\section{PROPAGATION}

THE Apple is increased either by budding or grafting. For the purpose of budding, stocks should be planted in November or December in order to be ready for budding 
in the following August and September. The Crab stocks are ready to bud before the Paradise stocks, and the work can be started when the shoots (or scions) of the varieties which are to be propagated are about three parts grown. The point of the scion shoot, being useless, can be cut off as far as it is sappy or green, and some six to eight buds at the base of the shoot, being dormant, should not be used. All the leaves may be removed, leaving the leaf-stalks on the scion for ease in handling the selected bud, which should be removed by making a slanting cut under the bud into the hard wood, starting $\frac{1}{4}$ inch above the bud and drawing out $\mathrm{I}$ inch below the bud.

This is best done by taking the scion in the left hand and holding it firmly on the thumb as a fulcrum. The knife is then held in the right hand, and the bud is scooped out by using the knife in a slanting position. The knife should be very sharp, as the cut must be clean. The looplike bud is then taken in the first finger and thumb of the left hand, and with the forefinger of the right hand the woody part is separated from the bark, leaving only, as it were, the skin remaining. If the base of the pin (or young bark bud) is then level with the green inside bark, it is a good one; but if in removing the wood this pin comes out with it and leaves a tiny hollow, that is a useless bud.

Previous to the removal of the bud, the stock should be prepared to receive it, as the bud must not be allowed to get dry. If it is a Crab stock, first make a cross cut about $\mathrm{I} 2$ inches from the ground, and then a down cut about $\mathrm{I} \frac{1}{2}$ inch long, the two cuts resembling the letter $\mathrm{T}$. Then insert the flat end of the budding knife under the edges below the cross cut, and lift up the 
PLATE VII

Pear: Pitmaston Duchess

(Ripens in November.) 



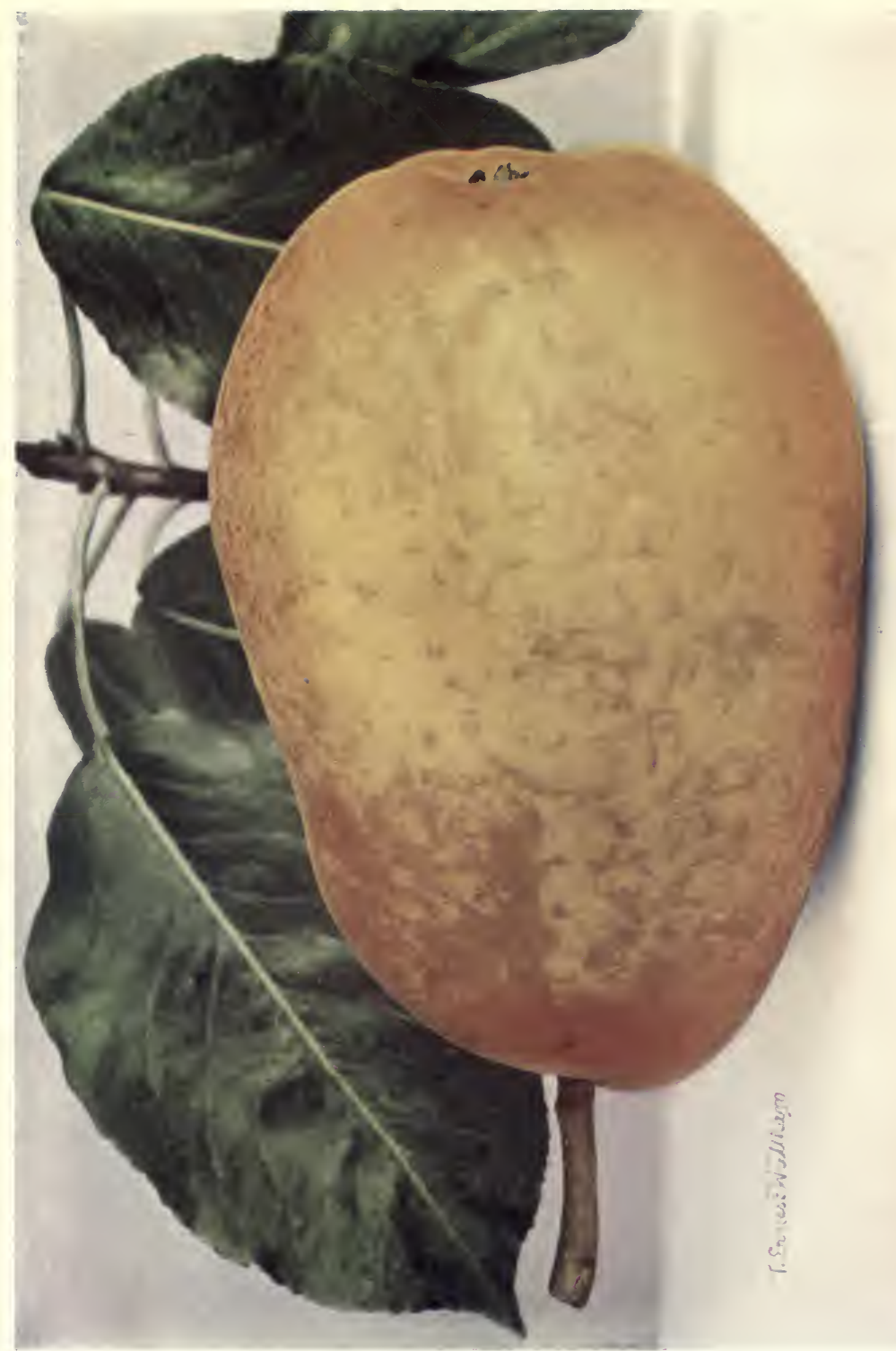


bark on both lips so that the bud can be inserted. Push down the bud so that the lower end touches the bottom of the opened bark, and fold over the right and left lips of bark to close it in. Should the upper part of the bud be too long for the incision in the stock, the top may be cut off to fit exactly in the position prepared for it in the stock, leaving the bud about half-way in the opening of the stock.

Always take care to have a good length below the bud, and that the bud is put in the right way up-that is, the leaf-stalk should point upwards.

The same manner of budding is carried out in placing buds on Paradise stocks, but in this case the bud is best inserted 2 inches or less above the ground.

As soon as the buds are inserted, tie them in tightly with Raphia bast-pieces about I5 inches long are beststarting below the bud with an equal length in each hand, and taking care to cross the matting so that it does not bury the bud. After the lapse of a month the ties may be removed, for the stock grows quickly, and if left tied, the matting cuts into the bark and causes a wound.

Grafting.-Grafting is performed in March or April, after the dwarf stocks have had one or even two years' growth in the quarters. First, the stock is headed back to $I_{5}$ inches. Then a clean side without knots is chosen, and it is cut so as to peel off about 4 inches of the bark, starting at the base and cutting upwards, to make a pattern like an inverted hairpin, cutting into the wood about $\frac{1}{8}$ of an inch at the upper end. Then a cross cut is made about $\frac{1}{4}$ of an inch deep in the stock, about $\mathrm{I} \frac{1}{2}$ inch from the top, merely a notch, by pressing a sharp, stout knife 


\section{PRESENT-DAY GARDENING}

downwards. The grafts are then prepared by cutting the lower end of the shoot about 6 inches long, cutting this length down from about the third eye of the upper end of the scion, and shaving the base off to next to nothing, and to match as far as possible the loop on the stock. If it is too long, more must be cut off ; then make an upward

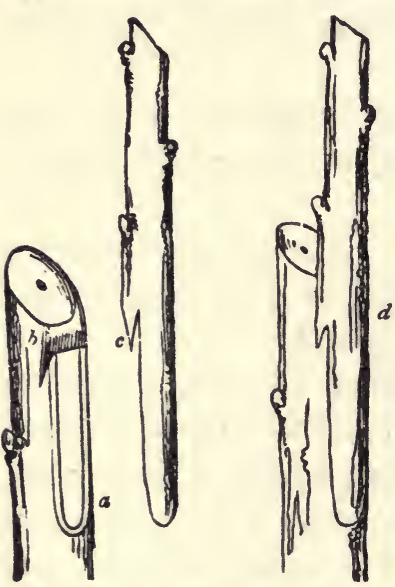

Fig. 5.-Grafting notch in the scion to fit into the notch on the stock, and press the scion and stock closely together. It is important that the bark at the base of the scion meets the bark at the base of the stock, as the healing growth starts at that point and a complete junction is then secured. In cutting the scion the wood should be slightly scooped out. If left rounded, it makes a bumpy union.

The graft or scion should be $a, b$, the stock prepared for grafting ; $c$, the scion; $d$, the graft completed.

(From the Gardeners' Chronicle.) then firmly tied in, and some mixture, either of wax made from grease and resin, or clay and horse droppings beaten into a pudding with a flat stick and afterwards well kneaded like dough. The material prepared is firmly placed all round the stock and scion to exclude the air. Special care should be taken to close the mixture well below the graft, and also above it, to keep out water. The "Pug" is made up in finishing to the shape of a long egg. In using wax, it is put on hot, and if the first finger is dipped in 
water, the needful finishing can be done without scalding the finger. The wax is first put on with a flat stick, rubbed on both sides of the graft.

When the buds have made growths about 8 inches long, they require to be tied to the upper portion of the stock above the bud. This is done by looping one round of the matting on the outer side of the growth, with two rounds encircling the stock; this leaves the needful free space for the bud growth to expand. In grafts, the growths require to be tied to a stake placed close to the stock, to keep them upright and to prevent the wind preaking the graft away from the stock. The snag of the stock above the bud should be cut away in October, in a slanting direction, to allow the new growths to swell over the stock and make a perfect union. In grafts, the wedge-shaped snag should be cut away for the same purpose.

The scions which it is proposed to graft should be cut in January or February and be tied in bundles of not more than twelve, then laid in by the heels one-third of their length in soil or sand in a shady position. This is done to make them "hungry" or partially dried, in order that they may more readily absorb the sap from the stock when grafted.

Where it is proposed to graft old trees, the boughs should be sawn off below the branches in February. On standards and dwarfs or bushes, the smaller boughs can be grafted, or, if espaliers, the arms must be cut back to I foot of the central stem. Tongue grafting, as advised for dwarf stocks, can be practised on small boughs, but on the larger ones an opening is made with a chisel and the 


\section{PRESENT-DAY GARDENING}

scion is cut with two wood sides and one bark side and forced into the cavity, the scion being pointed and made three-sided for the purpose. The wax or pug must cover the end of the bough as grafted, and very early in May the ties should be loosened, but not removed. Sticks should be attached to the bough to support the new growths, as the union at first from the new growth is very feeble, and, in the absence of ties, grafts are sure to blow out in a gale, or be forced out when any large bird settles on them. After one summer's growth, the new wood is again cut back; and even if the growth is long and free the first summer, it is wise to cut a foot off the ends in September to prevent an undue strain on the junction.

The growths in after-years are pruned according to the form of tree desired. But on standards the best method is to spur the side shoots, and leave only such long growths as are required for the purpose of extending the tree, or cutting others for the purpose of multiplying the branches. A pyramid and standard tree are illustrated on p. 80 .

It is somewhat difficult to put into words the exact operations of budding and grafting. Amateurs might grasp the work more readily if they could see it done by an expert, and we suggest this should be arranged if possible. Still, with the descriptions and drawings, it should not be difficult. We would advise amateurs at first practising on such easily raised barks as the Ash or Willow, or on Briar Rose, standards which do not necessitate stooping. In the nurseries the men put on 2500 to 3000 buds per day, with the help of a boy following behind them to make the ties. 


\section{PROPAGATION OF PEARS}

\section{PROPAGATION OF PEARS}

The methods for the propagation of Pears are precisely the same as for Apples. To form espaliers or standards, the wild Pear is used as a dwarf stock, budding the stock at a point $\mathrm{I} 2$ to $\mathrm{I} 5$ inches from the soil ; but for forming cordons, pyramid trees, or bushes, the Pears are budded low on Quince stocks. The wild Pear or "free" stock is ready for budding first; the Quinces are late in commencing to grow, therefore they are budded last.

In planting out young stocks the rows should be 3 feet apart, and the stocks should be planted ${ }_{15}$ inches apart in the row. "Free" stocks may be raised from "pips" (seeds) of the Pear and Apple ; these are best raised in pots in a cold frame, but larger quantities may be raised in a seed-bed of light soil.

Any wild Apples, Pears, or varieties of either fruit that are growing in unsuitable positions may be headed back and grafted with varieties suited to the conditions.

Double-grafting is carried out with certain varieties of Pears, which are incapable of succeeding when grafted direct upon the Quince stock. In these cases, a free-growing variety like Doyenné Boussoch, or Hessle, is first budded on to the Quince stock, and the next season the shoot from this bud is budded with the desired sort, say Marie Louise or Souvenir du Congrés; this latter bud is inserted 6 inches from the base of the mother shoot. Apples do not need double working, although such free growers as Peasgood's Nonsuch or Bramley's Seedling can be checked and made more prolific when grafted on a smaller wooded kind, like Cox's Orange Pippin or Worcester Pearmain. 


\section{PRESENT-DAY GARDENING}

\section{CHAPTER XXIV}

\section{CALENDAR OF OPERATIONS IN APPLE AND PEAR ORCHARDS}

\section{JANUARY}

APPLES now in the store should be carefully examined, and those that are not keeping well should be sorted over and the sound fruits marketed. The best prices are obtained by sending regularly, rather than by saving up for a Saturday's market. Get the manure on the land for digging-in. Complete the planting of trees; stake orchard standards and protect them from cattle. Winter pruning can be done in mild weather. Destroy bullfinches and sparrows. Fill up gaps in hedges and wind-shelters by planting afresh.

\section{FEBRUARY}

As Canadian and American Apples will soon arrive in large quantities, it will be well to market most of the fruit now in the store. Send the best to distant markets, as the "seconds" will sell to local buyers. At this season, large kitchen Apples make good prices, as imported fruits do not cook well. Digging should be completed as soon as possible. Towards the middle of the month any large trees which are to be grafted should be headed down, and the grafts to be put upon them should be procured, and be heeled-in in a shady place two-thirds of their lengths below 


\section{CALENDAR OF OPERATIONS 97}

ground, in bundles of thirty to forty, properly labelled. February is a good month to dress fruit-trees with the Caustic Wash.

\section{MARCH}

Newly planted trees require a mulch of half-long litter to prevent the sun drying the surface and injuring the upper roots; it is best to hoe over the surface round the tree before applying the mulch. By this month all digging and planting should be completed. Any fresh trees of Plums and Damsons, planted carefully before Christmas, may now be headed back, but all other trees should be allowed to make a year's growth before they are pruned. Insect life will now be awakening, and all prunings, bark-scrapings, rubbish, and hedge-cuttings should be collected for burning. Orchard trees must now be again greased to catch the spring species of moths that will be hatching and ascending the trees. The spraying apparatus should be put in order, and materials for use should be procured, as when the first buds begin to swell spraying must be started without delay. Where ground is rough after the winter digging, a dry period should be chosen for the men to break the clods in the plantations with Canterbury three-prong hoes. Grafting is best performed in March; the younger trees should be treated first, the old trees headed back in February, in which the flow of sap is less active, being left until last.

\section{APRIL}

If heavy rains have hardened the surface soil of plantations, it will pay to loosen it by means of the pony hoe or 


\section{PRESENT-DAY GARDENING}

by hand labour. This will kill small weeds, render the summer cultivation easier, and prevent that evaporation of moisture which goes on where land is hard and unmoved. Fruit-trees will now be blossoming, and great damage may be done by early frosts. This cannot always be prevented; but smother fires, so arranged that their smoke travels across the plantation, will often be of service. Weeds should be destroyed.

\section{MAY}

Apple blossom will now be abundant. The Apple sucker pest may necessitate spraying, and a late crop of winter moth larvæ may also be in evidence. A good spraying as soon as the petals of the blossoms fall will be advisable in plantations that have been injured in the past year ; the check to growth caused by cold nights and frosts is favourable to insect pests, and extra attention is required at this period. Weeds must be destroyed, and even when there are but few, the hoe will be of service in keeping a surface tilth. Towards the end of May, where trees are promising a heavy crop, a mulching of long strawy manure will be beneficial. It is of little use close to the stems, but should be spread over a circular space 6 feet wide at 3 feet from the main stems. If dry weather sets in, the soil round newly planted trees should be stirred and well pulverised, in case the surface may cake and crack; a mulch of short manure afterwards will be useful. Young trees that show signs of distress may be thoroughly watered. The growths from buds upon young stocks, if 9 inches in length, should now be tied to the stock for safety. Grafts inserted last March will now require the bands to be loosened 


\section{CALENDAR OF OPERATIONS 99}

and the pug or wax to be removed. See chapter on Propagation.

\section{JUNE}

The Brown Aphis on Apple shoots should be sprayed before they cause the foliage to curl. Place a mulch over the roots of those trees which are carrying heavy crops, if this work was not completed in May.

\section{JULY}

In the last weeks in July some of the early cooking Apples will be swelling to a useful size, and where the trees are heavily cropped it will pay to thin out the largest fruits for market, even if the price realised only pays for the labour, as the thinning will benefit the trees and allow the crop to develop more perfectly.

\section{AUGUST}

Continue to thin out Apples where the trees need it. Dessert Apples should be coloured before they are marketed. Remove the superfluous inner shoots of Pear and Apple trees which have been planted from two to seven years. The budding of Pears should be done in the second week, following with Apples. Early kitchen Apples are now wanted for tarts, and they often pay to send before they are fully fit. The thinning at three or four times helps the trees, especially bushes on the Paradise stock.

\section{SEPTEMBER}

Pears and Apples are now the main crops for market. Again we repeat the warning only to send the best to the important markets, selling the "seconds" locally. The 


\section{IOO PRESENT-DAY GARDENING}

summer pruning (as in August) can be continued; and even old trees where crops are gathered can have their boughs and surplus shoots removed, whilst all dead, leafless wood can be the better taken out when the foliage is on the rest of the tree. Extra long shoots upon young trees may be shortened, removing I 2 to 8 inches.

\section{OCTOBER}

During this month buyers who are thinking of planting should visit the nurseries and see the trees growing. Apples like King of the Pippins and Summer Golden Pippin, that are stored for a short time, may be gathered. Nearly all the market Pears will be fit to store this month. The snags or stock ends of grafted or budded dwarf trees may now be cut off. The main crop of Apples will require gathering, but do not hurry the work, as the few fruits that first drop will be maggoty, and perfect maturity is needful for Apples to be stored for a long time. They should always be stored dry. If the prices are fairly good, they may, perhaps, pay well to market from the tree; but Bramley's Seedling, Lord Derby, Newton Wonder, and Jubilee will pay for storing. Cox's Orange Pippin and choice dessert varieties will also pay for the extra trouble. Choice Pears must be laid singly on the shelves. All stored fruit must be looked over on wet days, and decayed examples removed before they infect the sound fruits near to them. As before stated, when a developed tree has been cleared of its fruit, the pruner should at once attend to the thinning of the branches and spurs, and the removal of dead branches. Old trees are greatly benefited by a dressing of Kainit, applying 5 cwt. per acre on the ground surface. 


\section{PLATE VIII}

Apple: Baumann's Red Reinette

(A good Apple for cultivation in towns.) 



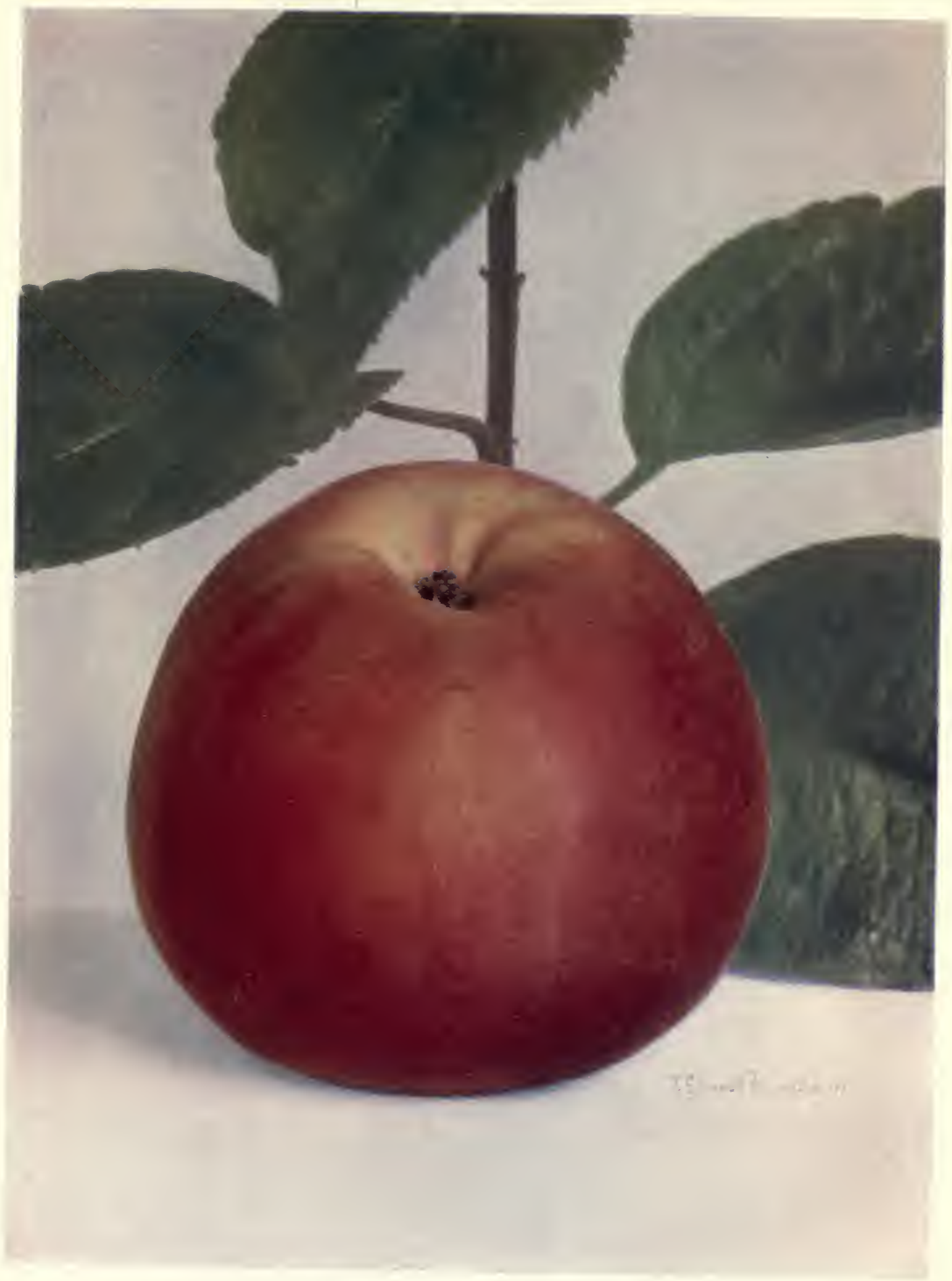





\section{CALENDAR OF OPERATIONS IO3}

Purchasers should now place their orders for trees and bushes required for the coming season, and procure wire netting, stakes, \&c., ready to support the trees when planted. About the middle of October the perfect insects of the winter moth begin to appear, therefore grease banding should at once be carried out on orchard trees, and the work should be completed by November 5 .

\section{NOVEMBER}

This is the chief planting month. Pears should be generally quite fit for removal by the second week in November, and Apples the second or third week, but the exact date will depend on the weather. A dry October may prevent lifting until November, because fruit-trees are apt to shrivel in transit if lifted too early or in dry weather.

\section{DECEMBER}

Continue planting. Cut down old and useless trees in frosty weather, and prune established trees. In large plantations it may be necessary to start pruning young trees; this can be safely done, except in very frosty weather. Collect manure for the winter spreading, before the diggers enter the plantations. Early manuring is good for bush fruits and young trees, but for orchards and plantations of Apples February is a good time to apply the manure. During the slack time in November and December scrape the loose bark off old tree stems and branches before the usual limewash is put on. If possible a cloth should be put under the trees so that the scrapings can be collected for burning. The limewash will kill eggs and larvæ of many enemies and make the bark smooth and healthy. 


\section{IO4 PRESENT-DAY GARDENING}

Some soft soap and soot may be stirred into the limewash, and it should be applied not only to the stems, but into the principal limbs. A good recipe is : first slake fresh lime to a paste, and to every gallon of this add I pint of paraffin, I lb. of salt, and I lb. of soft soap. The soap should be first dissolved in hot water, and then be added to the bulk, stirring all well together. Apply with a tar-brush on a long handle or whitewash brush. The salt and paraffin make the wash enter all the interstices, and are distasteful to insects. If soot is added, use a quart to a gallon of water, always keeping it well stirred. It is a good plan to market Apples that are fit at least fourteen days before Christmas, as at Christmas foreign produce is preferred. About January ro the demand again sets in for late culinary and dessert Apples. Rubbish of all kinds should be collected and burnt, spreading the ashes on the manure-heaps. Hedges can be repaired and old ties on the fruit-trees examined, renewing any that need it.

\section{CHAPTER XXV}

\section{APPLE COOKERY}

THE old saying-

"An Apple a day

Keeps the doctor away,"

has some truth in it. There is a valuable corrective element in the Apple (malic acid), and whether eaten raw (as is best) or taken as a drink in cider, this acid is no doubt an antidote to rheumatism. In those counties where cider 
is still given to the labourers, and used regularly in the country houses, gout, sciatica, and rheumatism are less frequent than where beer is the general beverage. It is also held that the use of cider tends to longevity. Baked Apples are most wholesome, and those who eat Apples and Pears freely do not, as a rule, suffer from thirst, and they are generally temperate people. Any one troubled with constipation will find great relief from eating baked Apples the last thing at night; whilst there is no more wholesome food than a well-made Apple pudding.

Stewed Apples and Pears are always appreciated, and the good housewife will know how to serve these fruits in many different forms.

The following are a few selected recipes for cooking and serving up dainty dishes and sweets of Apples.

First select the best Apples. The following are all good varieties for cooking, those which "fall" being most suitable for tarts and puddings, whilst the firmer ones are best for baking. They are placed in their order of ripening :-

Early Victoria, Potts's Seedling, Lord Grosvenor, Grenadier, Ecklinville Seedling, Stirling Castle, Golden Spire, Norfolk Beauty, and Blenheim Pippin.

For later use (November to March) - The Queen, Lord Derby, Lady Henniker, Roundway Magnum Bonum, Lane's Prince Albert, Alfriston, and Hambling's Seedling.

Lord Derby or Warner's King are recommended for tarts, but the wise cook will try many, and having once found a satisfactory fruit, will not lightly forsake it.

It is scarcely necessary to give a recipe for baked Apple tart, but the following is a pleasant variation :-

German Apple Tart.-Ingredients : Make a short crust 


\section{IO6 PRESENT-DAY GARDENING}

with half a pound flour, quarter pound butter, $2 \mathrm{oz}$. sugar. Work these together without adding any water. Roll out the pastry, slip it on to a flat, round tin, ornament the edges with a fancy strip, or little balls of paste, and cook the paste in a fairly hot oven for 45 minutes. Meantime, make a stiff marmalade of Apples flavoured with cinnamon, nutmeg, and sugar to taste. When the paste is cooked, take it from the oven, but do not lift it from the tin till cold, or it will break to pieces. When ready, lift it carefully on to a dish, ornament the edge with candied Cherries, spread the Apple marmalade smoothly on it, and serve.

Gateau des Pommes.-Take some acid, well-flavoured Apples, like Dumelow's Seedling (Wellington) or Bramley's Seedling, as those with an earthy taste give unsatisfactory results.

Ingredients : 2 lbs. Apples, 4 oz. white, moist sugar, $\frac{1}{2}$ pint water, I2 sheets gelatine, I lemon.

Melt the gelatine in half of the water. Peel and core the Apples and cut them fine. Put them into a lined saucepan with the sugar and the rind and juice of the lemon and the rest of the water. When the Apples are soft, add the gelatine, and cook for five minutes more. Rub through a sieve, and then pour into a well-wetted mould. This may be stuck over with split almonds, or garnished with whipped cream after turning it out.

Ordinary Apple pudding is too well known to need description, but "Town" Pudding is less often served, and it is very nice.

Town Pudding requires $3 \frac{1}{2}$ oz. suet, $3 \mathrm{oz}$. flour, $3 \mathrm{oz}$. breadcrumbs, $8 \mathrm{oz}$. finely chopped Apples, 2 oz. sugar, 
I egg, a little nutmeg. Mix all these together without adding any water, and press into a well-greased mould. Steam for $3 \frac{1}{2}$ hours. Let it stand for 5 minutes before turning out, and serve with cinnamon sauce.

To make this sauce, take I oz. cornflour, I teaspoon rum, I teaspoon sugar, I oz. butter, $\frac{3}{4}$ pint water, I stick cinnamon.

Mix the cornflour with a little of the water. Put the rest on to boil with the other ingredients. When boiling, pour it gradually on to the cornflour and put it back into. the saucepan to thicken and keep hot. Stir occasionally, and remove the cinnamon before serving.

A desirable pudding for the nursery is made by lining a basin with bread-and-butter, filling it up with well-flavoured Apple sauce and bread-and-butter placed in layers alternately, and pouring over it a custard made with two eggs and a pint of milk. Bake in a moderately warm oven for threequarters of an hour.

Baked Apples are apt to be uninteresting unless served very hot, and care should be taken to serve all Apple dishes as hot as possible, for they lose much of their attractiveness when served tepid. Half-an-hour in a fairly hot oven is enough to bake a good-sized Apple. To prevent bursting, it is well to prick the fruits three times with a skewer near the stalk, before putting them into the oven. Apples cored and peeled, and baked with a little strawberry jam in the centre, or simply basted with butter and sprinkled with sugar, are very good.

The following sweets are best cooked in a fireproof dish, being sent to the table in the dish in which they are baked. Any plain baked Apples left can have the pulp 


\section{IO8 PRESENT-DAY GARDENING}

scraped out and be used for curry, which is never so good as when there is Apple in its composition. Sweetened Apples may be used up in the same way for Apple Charlotte, although this is nicer made with Apples stewed to a marmalade, and flavoured with lemon and nutmeg.

Apple Charlotte.-Well butter a pie dish and line it with fresh breadcrumbs. Spread a layer of Apple marmalade on this, then a layer of breadcrumbs, and so on, finishing with a layer of crumbs. Put pieces of butter here and there on the top. It will take some 30 to 45 minutes to cook, according to size, and will be all the smoother if an ounce of butter is stirred into the Apple marmalade before the charlotte is made. If bread-and-butter is used instead of crumbs, and two tablespoonfuls of treacle are poured over the pudding, it is known as Brown Betty.

Compote of Apples is a favourite with those who like well-sweetened dishes. The following is a French recipe. "Compôte des Pommes." Take four or five Apples, preferably Norfolk Beauty or Ecklinville Seedling, halve, core, and peel them, dropping each piece when done into a basin of acidulated lemon water. Make a syrup of one pound of white loaf-sugar and half a pint of water. Drain the Apples from the water, put them in a lined saucepan or preserving pan, and pour the syrup over them. Add strips of lemon rind and a pod of vanilla. Bring quickly to the boil, and then draw the pan to the side of the stove and let the Apples simmer till they cook clear. Lift the pieces carefully into a dish with a silver spoon, and when cool pour the syrup over them. Serve quite cold. Thicker syrup can be made by boiling the juice till it jellies, after first lifting out the Apple. 
Stewed Apples._-Peel the Apples, which must be regular in shape and as much of a size as possible. Put them in a fireproof dish and just cover them with water, to which add two or three ounces of sugar, two or three drops of cochineal, and six cloves. Let them stew in the oven till quite soft, but not broken, and serve hot or cold. Stirling Castle or Golden Noble are good varieties for this purpose ; and Roundway Magnum Bonum, an excellent dessert Apple, can also be recommended for either tarts or baking.

Apples figure largely in several sorts of chutney, two of which are given below :-

Apple Chutney.-Ingredients : $3 \mathrm{lbs}$. Apples peeled and chopped, I quart vinegar, I lb. fine sliced onions, $\frac{1}{2} \mathrm{oz}$. ground ginger, $4 \mathrm{oz}$. salt, I lb. brown sugar, I lb. sultanas, $\frac{1}{\mathrm{oz}}$. fine chopped chillies, $\frac{1}{2} \mathrm{Oz}$. pepper, I clove of garlic if liked. Boil over a gentle fire, in an enamel pan, till the Apples and onions are soft. It will take about an hour. If very hot pickle is not liked, the pepper and half the chillies may be omitted.

Bengal Chutney requires $8 \mathrm{oz}$. moist sugar, $4 \mathrm{oz}$. mustard seed, $4 \mathrm{oz}$. raisins, $2 \mathrm{oz}$. onions, I pint of vinegar, $2 \mathrm{oz}$. garlic or shallot, $2 \mathrm{oz}$. whole ginger, quarter oz. cayenne pepper, I 2 sour Apples.

Stone and chop the raisins, pick over the mustard seed, slice and pound the onions and garlic. Peel and chop the Apples, boil them in the vinegar till soft, then pound them in a mortar. When quite cold, mix all the ingredients together, put up in small jars, and tie down closely. Patent glass screw-top jars are best for all pickles and jams. Both the above chutneys improve by keeping.

Pickled Apples.-Take Apples while still green and 


\section{IO PRESENT-DAY GARDENING}

hard, make a salt and water pickle thick enough to bear an egg, place the unripe Apples in this and stir them about. Leave for four days, stirring daily. Then lift the fruit from the brine, wipe and core, filling up the hollows with mustard made with vinegar. Have ready the following pickle, and pour it boiling hot over the Apples :-

I quart of vinegar, I oz. peppercorns; I oz. garlic, 8 oz. mustard seed, $\frac{1}{2} \mathrm{oz}$. whole ginger. Boil the liquor up again every alternate day for a week, letting it cool before pouring it back on the Apples. At the end of that time tie down firmly with bladder, and leave for a few months before eating.

Apple Bread and Apple Gingerbread are both eaten in France. The former is made by using half a pound of Apple pulp to every pound of flour, making the mixture up in the usual way with yeast. Half an ounce of yeast would be sufficient for this quantity. The dough will take a long time to rise, and will need little if any water.

Apple Gingerbread requires 8 oz. Apple syrup (see "Sucre des Pommes," page II3), $\frac{1}{4}$ oz. powdered ginger, 4 oz. butter, 8 oz. flour, I cap of candied peel. Work these together and bake in a brisk oven.

Crab-Apple Jelly.-Delicious jelly is made from the John Downie Crab, and if the following recipe is carefully followed, the result will be a brilliant, firm jelly. The Siberian, Dartmouth, and Transparent Crabs are also useful.

Wipe the Crabs and remove the stems, then put them in a large crock with just enough water to cover them, and stand this in the oven, with a plate over the top, till the Crabs begin to burst their skins. Turn them out into a large colander (which must be used for jam-making only) 


\section{CRAB-APPLE JELLY}

or into a piece of coarse muslin, until all the juice has drained away. Do not press them. Measure the liquid, allowing a pound of the best loaf-sugar to every pint of juice. Put the sugar into a preserving pan, pour the juice over it, and let it stand by the side of the stove until the sugar is dissolved. Then stand the pan over the fire and bring the jelly quickly to the boil, stirring and skimming until finished, which will take about fifteen minutes after it has begun to boil. At the end of ten minutes, put a little sample on a cold plate and stand it in a cool place. If it sets firm, take off the pan and put up the jelly in small jars, covering immediately with wax paper, and tying down as soon as possible. The pulp left after the juice has drained away must now be used. First, put it through a sieve or potato masher, to free it from the cores and pips. This latter method, although quicker, is very messy, and covers the cook with splashes. Weigh the pulp, and allow half to three-quarters of a pound of sugar to every pound of pulp. Put both together in a preserving pan and boil until firm. It will take a little under an hour. The jam is very stiff, and is apt to bubble up in little explosions, so that the jam-maker who consults the safety and comfort of her hands and face will wear gloves and use a long-handled spoon to stir it. If the larger quantity of sugar is used, the jam will turn out in the shape of the pot. It will keep best in small pots. Some families like sweet conserves and others prefer the fruit flavour to predominate, so that two quantities of sugar are named. The less sweet Crab pulp makes a fine sauce for game or mutton.

Apple Jelly is made in exactly the same way, and the following varieties are recommended: Bramley's Seedling, 


\section{PRESENT-DAY GARDENING}

Lane's Prince Albert, Tower of Glamis, Newton Wonder, Chelmsford Wonder, and Golden Noble; and, best of all, Cockle's Pippin, or a little, hard, red Apple sometimes found in old gardens, which is something like Winter Queening.

Windfall Jelly.-Wipe the Apples and remove the stalks, cutting away all decayed and bruised parts. Put into a jar with just enough water to cover them, and cook to a pulp in the oven. Measure the juice which has flowed from this, and to every pint allow one pound of loaf-sugar. Spice can be added in the proportion of six cloves, the rind and juice of a lemon, $\frac{1}{4} \mathrm{oz}$. of whole ginger, and one stick of cinnamon to every quart. Cook in the usual way, tying up the spice in a piece of muslin, and removing it before potting. This pulp may either be sieved and used for making chutney, either with equal weights of pulp and tomatoes, or, if alone, using to every pound as follows :-

4 oz. brown sugar, $4 \mathrm{oz}$. chipped onion, I oz. whole ginger, 4 oz. sultanas, I oz. chillies, I oz. salt, and enough previously boiled vinegar to bring it to the consistency of raspberry jam. The whole ginger should be removed before potting.

Where Apples are scarce, peelings can be used for jelly. This recipe is from Germany.

Apple Peel Jelly.-To every pound of Apple peel allow half a pound of sugar, the peel of half a lemon, and half a pint of water. Cook the water, Apple peel, and lemon together, adding the bruised pips and cores. When the water has reduced one-half, turn the whole into a basin, and when cold pour the juice on to the sugar, boiling both in the usual way until the mixture jellies. 
Sucre des Pommes, for which Rouen is celebrated, is made as follows. Take some dessert Apples and slice them very thin. To each pound of fruit add a pound of sugar and half a pint of water. Put all this in a jar and stand it in a saucepan of water on the stove, or in a cool oven for a couple of days; shake the contents, but do not stir at all. When cold, carefully pour off the syrup, put it into a preserving pan, and boil to the crack. Pour it out on a well-oiled marble slab, or large dish. Cut it across, and roll the sweetmeat into sticks. Wrap these in tinfoil or wax paper, use at once like barley-sugar, or store in air-tight tins or confectioners' glass jars.

Heringsalate.-Among foreign recipes the German Heringsalate and Italienschesalate, with Apples, are both very good.

For Heringsalate use 2 Apples, I 2 boiled potatoes, 2 oz. cold lean beef or veal, I teaspoonful mustard, 2 kippers cooked, 2 gherkins, I small onion, 2 dessertspoonfuls each of oil and vinegar, I pinch of pepper and salt. (In Germany the fish would not be cooked, but it is too strong for English taste raw.)

Cut onions, Apples, potatoes, gherkins, and beef into strips. Free the fish from bones, and cut it up also. Mix the whole with the oil, and finally add the vinegar, with which the salt, pepper, and mustard have been previously mixed. Serve directly. Sufficient for six people. Acid Apples should be used.

Italienschesalate requires 6 sardines, 6 cornichons (French pickled gherkins), 4 oz. ham, I small pickled cucumber, I Apple, 6 olives, 4 oz. cold cooked lean veal, I shallot (grated), 2 teaspoonsfuls of capers. 


\section{4 PRESENT-DAY GARDENING}

Free the sardines from the bones, break them into fillets, put them with the ham, veal, and Apple to marinade for an hour in the following mixture: 2 dessertspoonfuls clear stock, $\frac{1}{2}$ teaspoonful sugar, 2 dessertspoonfuls vinegar, I pinch of pepper and salt, the grated shallot. Then turn the meat on to a sieve to drain, chop up the cornichons, put them with the meat, and prepare the following dressing : 2 dessertspoonfuls oil, I pinch each of salt and pepper, I teaspoonful sugar.

Mix this dressing well with the salad, garnish with the sliced cucumber and capers, and serve directly.

Salad made in this way and dressed with mayonnaise is excellent.

Horseradish Sauce.-A novel sauce is made thus :-

2 dessertspoonfuls horseradish, 2 dessertspoonfuls vinegar, I small, sharp Apple, $\frac{1}{2}$ a saltspoonful each of salt and pepper.

Grate the horseradish and Apple, mix in the vinegar and condiments, and serve. British Apples should always be used in preference to foreign. When they are not obtainable, a tiny pinch of salt added to imported Apples will help to soften them in cooking.

Apple Fritters, Apple Snow, Apple Dumplings, and Turnovers have not been included in the recipes, as they are to be found in every cookery-book. Enthusiasts cannot do better than consult a little book published in I 864 by Routledge, called How to cook Apples, by Miss G. Hill. Even wine and cider making are described in its pages, and although the subject is inexhaustible, there are few aspects which have not received due consideration from the talented author. 


\section{STEWING AND BAKING PEARS II5}

Pears for Stewing and Baking.-When pears are plentiful, any sort can be used for stewing. After November the best will be Catillac or Pound Pear, which will keep till May and cook a good colour. Uvedale's St. Germain is a very good stewing variety of large size. As a late sort, Verulam or Black Worcester is valuable, and Vicar of Winkfield, which is ready at Christmas. Bellisime d'Hiver is also good then and bakes well. In a cold season any of the Pears which do not ripen well in store can be utilised for cooking; but they must always be slowly stewed, and if cloves are added the round bud at the top must first be removed, or the colour of the juice will be spoiled. Red Beet sliced makes a good colouring for stewed Pears; or cochineal.

As this book may be handed to cooks who are not familiar with weights, it may be as well to state that $4 \mathrm{oz}$. are a quarter of a pound, $8 \mathrm{oz}$. half a pound, and I2 oz. three-quarters of a pound; that a new penny weighs a quarter of an ounce, two pennies half an ounce, and four pennies one ounce. 


\section{NDE X}

APPLE, pests of the, 54

American blight, 56

aphides, 56

Apple sucker, 6 I

canker, 60

caterpillar pest, the, 55

mildew, 6I

mussel scale, $6 \mathrm{I}$

Pear midge, 62

Pear slugworm, 63

red spider, 60

weevils, 59

Apple and Pear culture for profit-

Apples for the markets, 75

blocks of one variety not desirable, 67 bush fruits for planting between Apples and Pears, 8I

cheap land, 69

choice Pears for bushes, 77

cultivation for profit, 66

land near a town or railway, 69

late Apples for storing, 77

number of trees per acre, 80

packing fruit for sale, 83

Pears as standards, 78

Pears for stewing and baking, II 5

planting, 72

preparation of land, 72

probable market prices, 82

propagation, (budding of Apples) 87, (grafting) 9 I

propagation of Pears, 95

pruning, 18,70

purchase of land, 69

purchase of trees, $7 \mathbf{I}$

shelter, 7 I

standards or half-standards in orchard or plantations, $8 \mathrm{I}$

too many inquiries, 68

too many varieties, 67

value of fowls, 72

ways and means, 86

wiring hedges, 70

Apple cookery, IO4

Apples-

dessert, for exhibition in August or September, 32
Apples (continued) -

for exhibition purposes, 32

for October and later, 33

for pot culture, 39

for the Northern Counties and Scot-

land, 34

select list of, 27

some of the newer cooking, 32

some of the newer dessert, 31

Arches and pergolas, II

Calendars of operations, 63,96

ESPALIER trees, treatment of, 20

FAN-TRAINED trees on walls, 22

Feeding and thinning, 47

GATHERING and storing the fruit, 52

Historical notes, I

Horizontal trees on walls, 22

OPERATIONS for the year, monthly calendars of, 63,96

Orchard houses, Apple and Pear culture in, 35

Pears, choice, 49

for cordons, 50

for the North of England and Scotland, 50

Pests of the Apple, 54

Planting, method of, 16

Preparation of soil, 15

Pruning, 18, 70

Purchase of trees, ro

ROOT-PRUNING, 23

SITE, choice of, Io

Soil, preparation of, 15

Summer pruning, 23

TeRMS used to describe types of fruit, 9

Trees, purchase of, 10

UNFERTILITY, 62

VARIETIEs of Apples and Pears for particular aspects, 12

Printed by Ballantyne, Hanson $\&$ Co.

Edinburgh \& London 


\section{UNIVERSITY OF CALIFORNIA LIBRARY BERKELEY}

Return to desk from which borrowed.

This book is DUE on the last date stamped below.

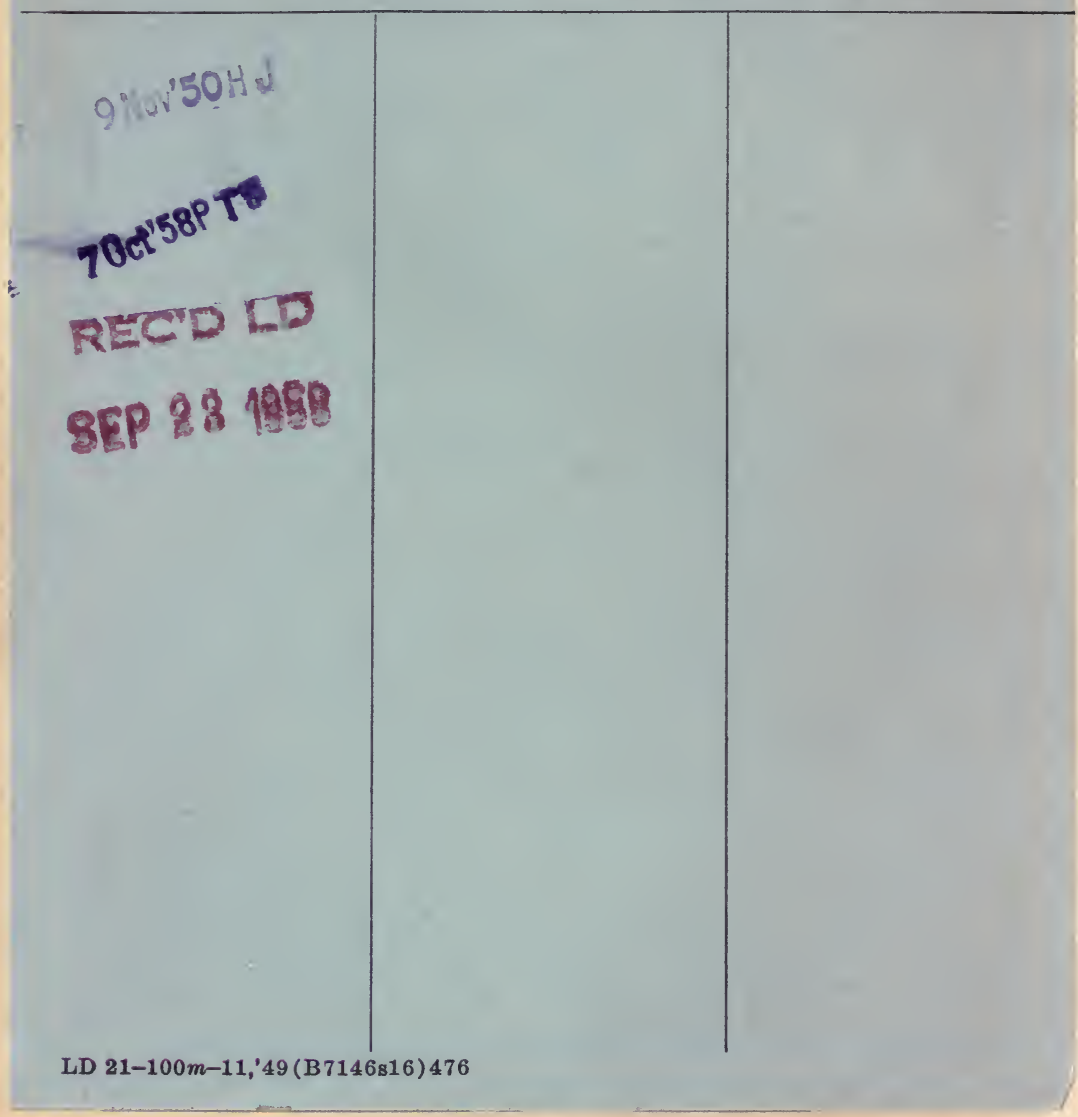




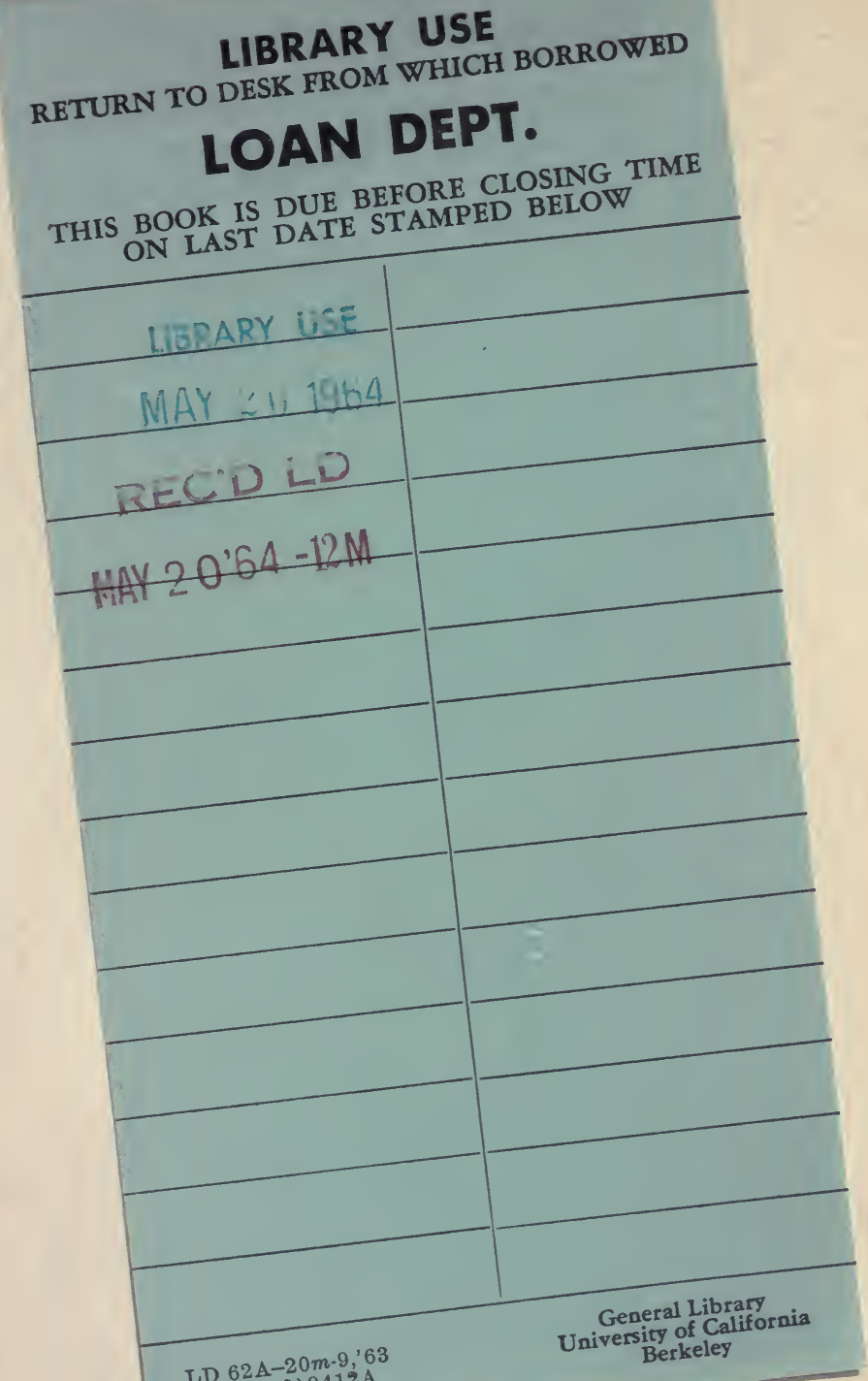

D $62 \mathrm{~A}-20 \mathrm{~m}-9,6$

(E709810)9412A 
